See discussions, stats, and author profiles for this publication at: https://www.researchgate.net/publication/221790069

\title{
Culture and the Distinctiveness Motive: Constructing Identity in Individualistic and Collectivistic Contexts
}

Article in Journal of Personality and Social Psychology · January 2012

DOI: 10.1037/a0026853 · Source: PubMed

CITATIONS

60

40 authors, including:

Maja Becker

Université Toulouse II - Jean Jaurès

39 PUBLICATIONS 407 CITATIONS

SEE PROFILE

Rupert Brown

University of Sussex

182 PUBLICATIONS 14,932 CITATIONS

SEE PROFILE

Some of the authors of this publication are also working on these related projects:

Project Teachers' Efficacy beliefs, emotional intelligence, quality of life, and collective efficacy View project

Children with Disability Related Research View project
READS

1,062

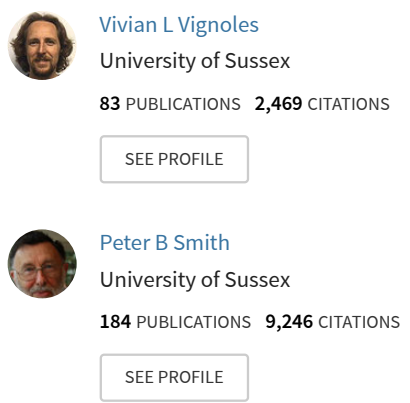




\section{Culture and the Distinctiveness Motive: Constructing Identity in Individualistic and Collectivistic Contexts}

Maja Becker, Vivian L. Vignoles, Ellinor Owe, Rupert Brown, Peter B. Smith, and Matt Easterbrook University of Sussex

David Bourguignon

Paul Verlaine University-Metz

Flávia Cristina Silveira Lemos

Federal University of Pará

Silvia H. Koller

Federal University of Rio Grande do Sul

Qian Wang

Chinese University of Hong Kong

Elvia Vargas Trujillo and Paola Balanta

Universidad de Los Andes

Kassahun Habtamu Mekonnen

University of Addis Ababa

Marta Fülöp

Hungarian Academy of Sciences

Charles Harb

American University of Beirut

Mariana Martin

University of Namibia

Aneta Chybicka

University of Gdańsk

Johanna Buitendach

University of KwaZulu Natal
Ginette Herman and Isabelle de Sauvage

Université Catholique de Louvain

Ana Torres and Leoncio Camino

Federal University of Paraíba

M. Cristina Ferreira

Salgado de Oliveira University

Roberto González, Diego Carrasco, Maria Paz Cadena, and Siugmin Lay Pontificia Universidad Católica de Chile

Michael Harris Bond

Polytechnic University of Hong Kong

Aune Valk

Estonian Literary Museum

George Nizharadze

Free University of Tbilisi

Camillo Regalia, Claudia Manzi, and

Maria Brambilla

Catholic University of Milan

Said Aldhafri

Sultan Qaboos University

Ma. Elizabeth J. Macapagal

Ateneo de Manila University

Alin Gavreliuc

West University of Timisoara

Inge Schweiger Gallo

Universidad Complutense de Madrid

Emre Özgen, Ülkü E. Güner, and Nil Yamakoğlu

Bilkent University

The motive to attain a distinctive identity is sometimes thought to be stronger in, or even specific to, those socialized into individualistic cultures. Using data from 4,751 participants in 21 cultural groups (18 nations and 3 regions), we tested this prediction against our alternative view that culture would moderate the ways in which people achieve feelings of distinctiveness, rather than influence the strength of their 
motivation to do so. We measured the distinctiveness motive using an indirect technique to avoid cultural response biases. Analyses showed that the distinctiveness motive was not weaker-and, if anything, was stronger-in more collectivistic nations. However, individualism-collectivism was found to moderate the ways in which feelings of distinctiveness were constructed: Distinctiveness was associated more closely with difference and separateness in more individualistic cultures and was associated more closely with social position in more collectivistic cultures. Multilevel analysis confirmed that it is the prevailing beliefs and values in an individual's context, rather than the individual's own beliefs and values, that account for these differences.

Keywords: identity, motivation, culture, distinctiveness, self-concept

A common view in personality and social psychology is that people strive to distinguish themselves from others and that they have a basic motive to achieve distinctiveness. However, this view has been challenged in cross-cultural psychology, where it is sometimes asserted that the strength of this motive varies by culture. In some cultures, it is claimed, people want to be distinguished as individuals, whereas in others, people want to be part of larger entities and may even seek to avoid distinctiveness from other members of those entities (Triandis, 1995; see also Kim \& Markus, 1999; Markus \& Kitayama, 1991). Nevertheless, until now this assertion has not been tested appropriately. In this article, we examine whether and how the motive for distinctiveness may be moderated by culture.

\section{Distinctiveness as a Core Psychological Motive}

The concept of distinctiveness plays a central role in several social psychological theories of self and identity processes. For example, uniqueness theory (Snyder \& Fromkin, 1980) posits that people need to see themselves as unique and different from others in the interpersonal domain. In intergroup contexts, social identity theory proposes that people's actions can often be understood as attempts to maintain or restore distinctiveness for their ingroup in relation to some outgroup(s) (Tajfel \& Turner, 1986). Brewer's (1991) optimal distinctiveness theory suggests that competing needs for inclusion and distinctiveness underlie people's choices of, and satisfaction with, group memberships: People prefer groups that are neither so large as to threaten people's need to be distinct nor so small as to frustrate their need to feel included.

Reflecting the commonality among these theories, the need for distinctiveness is conceptualized here as an identity motive. Motivated identity construction theory (MICT; Vignoles, 2011; Vignoles, Regalia, Manzi, Golledge, \& Scabini, 2006) is based on the idea that identity is constructed through a complex interplay of cognitive, affective, and social interaction processes, all of which
This article was published Online First January 30, 2012

Maja Becker, Vivian L. Vignoles, Ellinor Owe, Rupert Brown, Peter B. Smith, and Matt Easterbrook, School of Psychology, University of Sussex, Brighton, United Kingdom; Ginette Herman and Isabelle de Sauvage, Unité de psychologie sociale et des organisations, Université Catholique de Louvain, Louvain-la-Neuve, Belgium; David Bourguignon, Laboratoire INTERPSY-ETIC, Paul Verlaine University-Metz, Metz, France; Ana Torres and Leoncio Camino, Department of Psychology, Federal University of Paraíba, João Pessoa, Paraíba, Brazil; Flávia Cristina Silveira Lemos, Department of Psychology, Federal University of Pará, Belém, Pará, Brazil; M. Cristina Ferreira, Department of Psychology, Salgado de Oliveira University, Sao Goncalo, Rio de Janeiro, Brazil; Silvia H. Koller, Department of Psychology, Federal University of Rio Grande do Sul, Porto Alegre, Rio Grande do Sul, Brazil; Roberto González, Diego Carrasco, Maria Paz Cadena, and Siugmin Lay, School of Psychology, Pontificia Universidad Católica de Chile, Santiago, Chile; Qian Wang, Department of Psychology, Chinese University of Hong Kong, Hong Kong, Special Administrative Region of the People's Republic of China; Michael Harris Bond, Department of Applied Social Sciences, Polytechnic University of Hong Kong, Hong Kong, Special Administrative Region of the People's Republic of China; Elvia Vargas Trujillo and Paola Balanta, Department of Psychology, Universidad de Los Andes, Bogotá, Colombia; Aune Valk, Estonian Literary Museum, Tartu, Estonia; Kassahun Habtamu Mekonnen, Department of Psychology, University of Addis Ababa, Addis Ababa, Ethiopia; George Nizharadze, Department of Social Sciences, Free University of Tbilisi, Tbilisi, Georgia; Marta Fülöp, Institute for Psychology, Hungarian Academy of Sciences, Budapest, Hungary; Camillo Regalia, Claudia Manzi, and Maria Brambilla, Centre for Family Studies and Research, Catholic University of Milan, Milan, Italy; Charles Harb, De- partment of Social and Behavioral Sciences, American University of Beirut, Beirut, Lebanon; Said Aldhafri, Department of Psychology, Sultan Qaboos University, Al Khoudh, Muscat, Oman; Mariana Martin, Department of Human Sciences, University of Namibia, Windhoek, Namibia; Ma. Elizabeth J. Macapagal, Department of Psychology, Ateneo de Manila University, Quezon City, Metro Manila, Philippines; Aneta Chybicka, Department of Cross-Cultural Psychology, University of Gdańsk, Gdańsk, Poland; Alin Gavreliuc, Department of Psychology, West University of Timisoara, Timisoara, Romania; Johanna Buitendach, School of Psychology, University of KwaZulu Natal, KwaZulu-Natal, South Africa; Inge Schweiger Gallo, Department of Social Psychology, Universidad Complutense de Madrid, Madrid, Spain; Emre Özgen, Ülkü E. Güner, and Nil Yamakoğlu, Department of Psychology, Bilkent University, Ankara, Turkey.

Preliminary analyses have been presented at the 4th African Region Conference of the International Association of Cross-Cultural Psychology (IACCP), Cameroon, Central Africa, 2009; the 20th Congress of the IACCP, Australia, 2010; the British Psychological Society Social Psychology Conference, Winchester, United Kingdom, 2010; and the Society for Personality and Social Psychology Conference, San Antonio, Texas, 2011. This work was funded by Economic and Social Research Council (United Kingdom) Grant RES-062-23-1300 to Vivian L. Vignoles and Rupert Brown.

Correspondence concerning this article should be addressed to Maja Becker, who is now at the CLLE (CNRS, UTM, EPHE), "Cognition, Langues, Langage et Ergonomie," Maison de la recherche, 5 allées A. Machado, 31058 Toulouse Cedex 9, France. E-mail: mbecker@univtlse2.fr 
occur within particular cultural and local meaning systems. These processes are understood to be guided by particular motives or "tendencies toward certain identity states and away from others" (Vignoles, 2011, p. 405). According to MICT, the motive for distinctiveness has a guiding influence on these processes of identity construction, together with at least five other motives. Specifically, the theory proposes that people are generally motivated to achieve and maintain feelings of self-esteem, continuity, distinctiveness, belonging, efficacy, and meaning within their identities.

Regarding the distinctiveness motive, there is substantial evidence of the many ways that people seek to construct and maintain distinctiveness of both individual and group identities (for reviews, see Lynn \& Snyder, 2002; Vignoles, 2009). People typically remember information better if it distinguishes the self from others (Leyens, Yzerbyt, \& Rogier, 1997), are most likely to mention their more distinctive attributes when asked to describe themselves (McGuire \& Padawer-Singer, 1976), and consider their more distinctive attributes as especially self-defining (Turnbull, Miller, \& McFarland, 1990; Vignoles et al., 2006). People also maintain and enhance distinctiveness of their group identities by ingroup stereotyping (van Rijswijk, Haslam, \& Ellemers, 2006), by derogating ingroup imposters and deviants (Jetten, Summerville, Hornsey, \& Mewse, 2005; Marques \& Paez, 1994), and by discriminating against outgroups (Jetten, Spears, \& Postmes, 2004). When feelings of distinctiveness are threatened or undermined, people typically report reduced psychological well-being, and they attempt in various ways to restore distinctiveness (Fromkin, 1970, 1972; Jetten et al., 2004; Markus \& Kunda, 1986; Pickett, Silver, \& Brewer, 2002; Powell, 1974; Snyder \& Endelman, 1979).

Vignoles et al. (2006) reported four studies among diverse groups of participants in the United Kingdom and Italy that showed the influence of the motive for distinctiveness on identity construction even when controlling for the influence of five other identity motives. Each participant freely listed 12 aspects of his/her identity (e.g., "woman," "friend," "musician," "ambitious") and then rated each identity aspect for its perceived centrality within identity as well as the extent to which it satisfied each of the six identity motives proposed in MICT. In all four studies, participants typically perceived as more central and self-defining those aspects of their identities that they felt distinguished them to a greater extent from others. The effect of distinctiveness on perceived centrality remained significant after accounting for the effects of other identity motives (for self-esteem, continuity, belonging, efficacy, and meaning), and a longitudinal test of the model showed that distinctiveness had a significant prospective effect on perceived centrality, whereas the reverse causal direction was not supported.

\section{Distinctiveness and Culture}

However, all of this evidence for distinctiveness-seeking comes from European and North American research. Cross-cultural theorists have suggested that the motive for distinctiveness may be culturally specific. Indeed, in his classic text on cultural individualism and collectivism, Triandis (1995) has proposed that the motive for distinctiveness will be stronger in individualistic cultures and weaker in collectivistic cultures. Underlying this prediction is the assumption that identity motives are derived from internalization of cultural values - that people who live in cultures where distinctiveness is valued will come to internalize this value, and it is for this reason that they will seek to construct distinctive identities (see, e.g., Breakwell, 1987; Markus \& Kitayama, 1991; Snyder \& Fromkin, 1980).

In contrast with this position, others have proposed that the need for distinctiveness is a "universal human motive" (Brewer \& Pickett, 1999, p. 85). Vignoles and collaborators (Vignoles, 2009; Vignoles, Chryssochoou, \& Breakwell, 2000) have argued that establishing some form of distinctiveness is a logical precondition for the existence of a meaningful sense of identity in any cultural meaning system. This suggests that people would be motivated to seek distinctiveness, whether they are living in a collectivistic or an individualistic culture. Brewer and Roccas (2001) have even argued that distinctiveness strivings may be stronger in collectivistic cultural settings, compared to individualistic ones, as the motive will be more frustrated - and thus aroused - in the context of a cultural system where distinctiveness is not valued or is even discouraged (for a similar argument, see Lo, Helwig, Chen, Ohashi, \& Cheng, 2011).

However, even if the distinctiveness motive is culturally universal, Vignoles et al. (2000) suggested that cultural systems may come to emphasize different forms of distinctiveness, and these emphases should be reflected in the identities of cultural members. They proposed that distinctiveness can be constructed in three ways: through difference, separateness, or social position, as illustrated in Figure 1. The most common way of operationalizing distinctiveness in psychology is as difference, that is, distinctiveness in qualities such as abilities, opinions, personality, and appearance. In contrast, social position refers to distinctiveness in one's place within social relationships, including kinship ties, friendships, roles, and social status. Separateness refers to distinctiveness in terms of boundedness or distance from others, including physical and symbolic boundaries, and feelings of privacy, independence, and isolation. Although they viewed the motive for distinctiveness as universal, Vignoles et al. hypothesized that cultural beliefs and values would moderate the ways in which this motive is satisfied. In other words, the strength of the motive would be similar across cultures, but people would find different ways of satisfying the motive-ways that fit their own cultural meaning systems.

More precisely, Vignoles et al. (2000; Vignoles, 2009) hypothesized that difference and separateness would be emphasized and valued more as sources of distinctiveness in individualistic cultures, reflecting the Western concept of the person as unique and bounded (Geertz, 1975). On the other hand, they hypothesized that
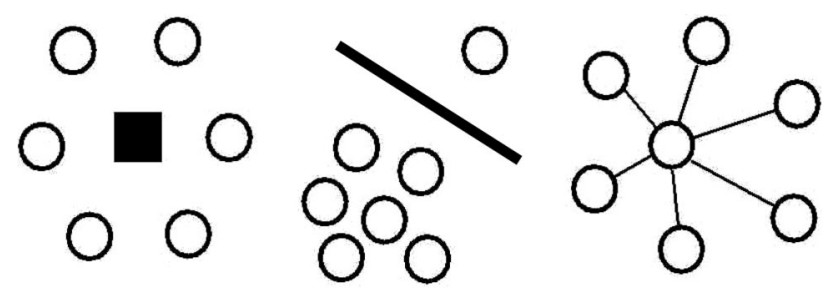

DIFFERENCE SEPARATENESS SOCIAL POSITION

Figure 1. Sources of distinctiveness (adapted from Vignoles et al., 2002) 
social position would be emphasized and valued more in collectivistic cultures, where the place of the individual within a network of social relationships is a significant aspect of the concept of personhood (e.g., Ho, 1993; Hsu, 1985).

\section{Measuring Distinctiveness-Seeking Across Cultures}

Evidence for cultural differences in the distinctiveness motive is mostly limited to a small number of studies using explicit selfreport measures of need for uniqueness (NFU). Yamaguchi, Kuhlman, and Sugimori (1995) reported somewhat lower mean NFU scores among Japanese and Korean undergraduates compared to Americans, although statistical significance was not tested. Burns and Brady (1992) found significantly lower mean NFU scores among Malaysian than U.S. business students; however, this difference appeared only on the Lack of Concern for Others subscale, suggesting a cultural difference in concern for social acceptance rather than in the desire for uniqueness per se. Tafarodi, Marshall, and Katsura (2004) found no difference between Japanese and Canadian undergraduates in overall NFU scores, although Japanese participants scored lower on items reflecting "desire to be different." These findings thus provide only limited evidence for cultural variation in the distinctiveness motive.

\section{Measuring Distinctiveness-Seeking}

A concern with these studies is that the measurement of distinctiveness motivation is based on participants' self-reports in response to direct questions about how much they want to be different from others. As noted by Vignoles (2009), explicit NFU scales may be measuring the subjective value placed on uniqueness and difference rather than the respondent's underlying psychological motives. People are generally aware of their values, whereas they may or may not be aware of their motives, and the two do not necessarily coincide. For example, when research participants in North America and Western Europe claim to value being unique and different from others, this may be a way of conforming with prevailing social norms-ironically, by saying that they want to be different from others, these participants are fitting in with their social environments rather than distinguishing themselves from others (see Jetten, Postmes, \& McAuliffe, 2002; Salvatore \& Prentice, 2011). Hence, it may be preferable to measure the distinctiveness motive using more indirect techniquesperhaps especially when looking at cultural differences (for related arguments, see Hofer \& Bond, 2008; Kitayama, Park, Sevincer, Karasawa, \& Uskul, 2009).

Kim and Markus (1999, Study 3) tested the hypothesis of cultural differences in preferences for uniqueness without asking participants directly how much they wanted to be unique. They asked travelers at an airport to complete a short survey, offering them the choice of a pen in return. Participants were presented with five pens that were identical except for their external color. The ratio of uncommon (unique) to common (majority) colored pens was 1:4 or 2:3. Participants were categorized as American or East Asian (Korean or Chinese), and results indicated that Americans were more likely to choose the uncommon pens than were East Asians. This finding has been cited frequently as providing evidence for a stronger preference for uniqueness among Westerners (e.g., Heine, Lehman, Peng, \& Greenholtz, 2002; Stephens, Markus, \& Townsend, 2007; Walsh \& Smith, 2007).

However, the dependent measure of pen choice is open to alternative interpretations. East Asian participants could have viewed the unique pen as more desirable, just as the Americans did, but had other reasons for not choosing it. Indeed, Yamagishi, Hashimoto, and Schug (2008) have shown that, rather than cultural differences in preference for uniqueness, these results are better explained by cultural differences in the behavioral strategies that individuals rely on in ambiguous situations: Compared to Americans, East Asians are more likely to be concerned about how they will be evaluated by other individuals, which makes them choose the unique pen less frequently. Beyond this debate about the interpretation of the findings, the different colored pen in this paradigm only relates to one of the three sources of distinctiveness identified by Vignoles et al. (2000). Therefore, even if Kim and Markus (1999) are right in their interpretation, this only shows cultural variation in striving for difference (as one possible source of distinctiveness). It does not necessarily indicate variation in striving for distinctiveness as such.

Vignoles and Moncaster (2007) devised an alternative way of measuring individual differences in the strength of the distinctiveness motive (and other identity motives), also without asking participants directly how much they wanted to be distinctive. As in the studies of Vignoles et al. (2006) described earlier, participants listed freely a number of aspects of their identities, and then they rated each identity aspect for its perceived centrality within their subjective identity structures - that is, the extent to which they perceived it as important and self-defining - and for the degree to which it provided feelings that would satisfy each of the motives they were interested in-for example, the extent to which it made them feel that they were distinguished in any sense from other people (for satisfaction of the distinctiveness motive). As in the earlier studies, the motive satisfaction ratings were used to predict the relative priority given to different aspects of identity within participants' subjective identity structures, but Vignoles and Moncaster's analyses focused on individual differences rather than testing the overall strength of each motive across their sample. They reasoned that people with a relatively strong motive for distinctiveness should show a relatively strong tendency to prioritize those aspects of their identities that they considered to distinguish them most from others and to marginalize those aspects of their identities that did not satisfy this motive (for an illustration, see Figure 2: Participant A); in contrast, this tendency should be weaker among those with a weaker motive for distinctiveness (see Figure 2: Participant B). Thus, individual differences in the strength of association between distinctiveness ratings of aspects of identity and their perceived centrality within subjective identity structures could be used as an indirect measure of individual differences in the strength of the distinctiveness motive.

Scores on this indirect measure have been used successfully to predict several theorized outcomes of the distinctiveness motive, including individual differences in national favoritism (Vignoles \& Moncaster, 2007) and in the preference for more or less distinctive relationship partners (Petavratzi, 2004). Yet, they are largely independent of explicit self-reports of NFU (Eriksson, Becker, \& Vignoles, 2011), indicating that they are not simply measuring participants' beliefs about how much they want to be distinctive, or the subjective value they place on uniqueness. Although the mea- 
Participant A

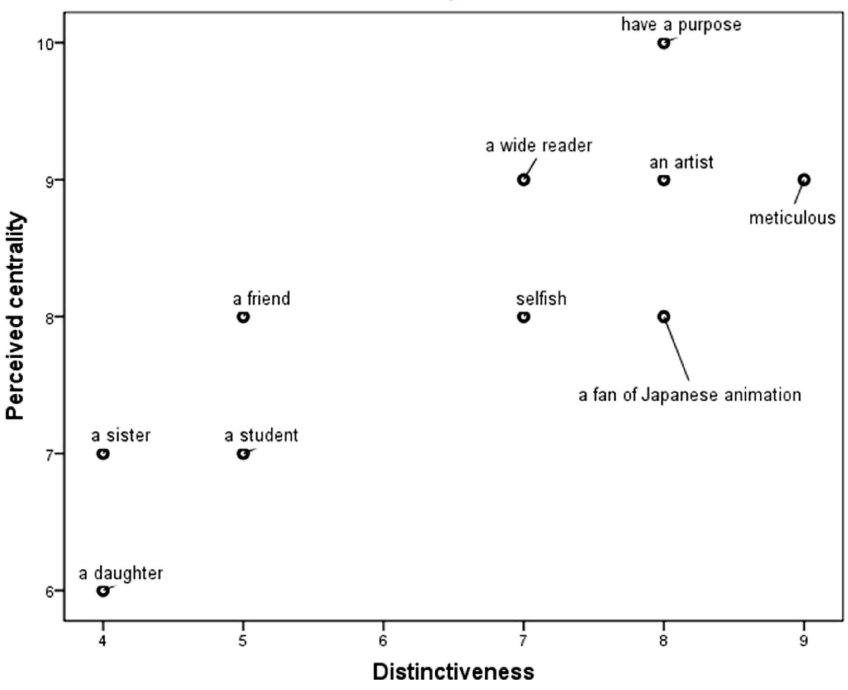

Participant B

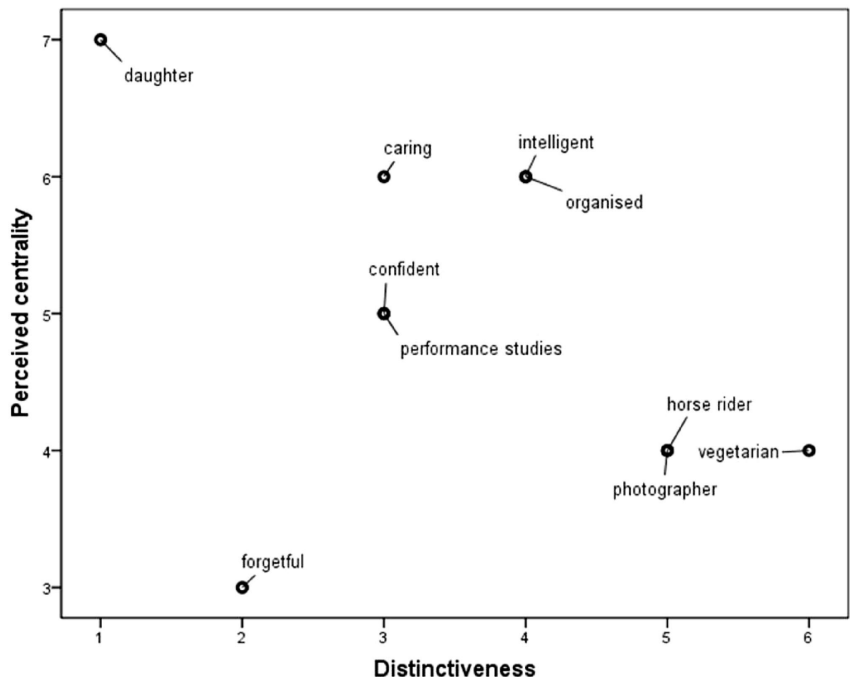

Figure 2. Examples of subjective identity structures from two participants. A more positive correlation between the feeling of distinctiveness from other people that an aspect of identity provides and the perceived centrality of that aspect within identity suggests a stronger motive for distinctiveness. Here, Participant A appears to have a stronger motive for distinctiveness than Participant B.

sure is derived from explicit self-reports about the perceived centrality and the distinctiveness of different aspects of identity, participants are unlikely to be aware of the statistical patterns within their responses that are the focus of the measurement. Hence, the measure arguably can be characterized as an implicit measure (a similar example is the Name Letter Task, which is derived from explicit self-report data but is widely understood as a measure of implicit self-esteem; see Krause, Back, Egloff, \& Schmukle, 2011; LeBel \& Gawronski, 2009).

This approach to measuring identity motives is also well suited for cross-cultural research. Because analysis is focused on withinparticipant relationships in the data, this measurement technique is insulated from several common sources of methodological bias in cross-cultural research, including the reference-group effect (Heine et al., 2002) and acquiescent response bias (Smith, 2004a). In the only cross-cultural study to date, Eriksson et al. (2011) found no difference between British and Swedish participants on this indirect measure of the distinctiveness motive, despite the fact that they did find national differences on an explicit self-report scale of NFU that were partially mediated by individuals' value orientations. Thus, superficial differences in self-reported distinctiveness-seeking were not replicated at this underlying level.

\section{Measuring Culture}

An additional concern about previous studies into culture and distinctiveness is their restricted operational definition of culture. With the exception of Eriksson et al. (2011), all of the crosscultural studies reviewed above have been based on bicultural comparisons between North American and East Asian participants, assumed to represent differences on the broad cultural dimension of individualism-collectivism. Although bicultural comparisons undoubtedly provide a valuable starting point in cross-cultural research, exclusive reliance on studies of this kind is problematic for several reasons.

First, no pair of nations can possibly represent the world's individualistic and collectivistic cultures more generally. Even if they are carefully selected, they will still inevitably differ from each other in many ways apart from their levels of individualismcollectivism. Moreover, East Asian nations, such as Japan and South Korea, are relatively atypical of the world's collectivistic cultures, both in their relative affluence and in their Confucian philosophical heritage. Just as one would not draw conclusions about the personality dimension of introversion-extraversion by comparing the behavior of a single introvert with that of a single extravert, so it is necessary to study a sample of cultural groupsand to sample these groups as widely as possible - if one wants to draw firmer conclusions about the implications of a given cultural dimension (Smith, Bond, \& Kağitçibaşi, 2006).

Although many researchers still base their characterization of national cultures on anecdotal evidence (or sometimes, it has been argued, on stereotypes; see Takano \& Osaka, 1999), several empirically based national indices of individualism-collectivism have been published by cross-cultural organizational psychologists. The best known of these is Hofstede's (1980) individualism index; however, Hofstede derived this measure from data collected around 40 years ago for an entirely different purpose, and the items have questionable face validity as a measure of individualismcollectivism (see Smith et al., 2006). More recently, the Global Leadership and Organizational Behavior Effectiveness (GLOBE) project has produced nation scores for 18 cultural dimensions based on a survey spanning 62 nations (House, Hanges, Javidan, Dorfman, \& Gupta, 2004). The GLOBE project's index of ingroup collectivism practices is closely related both theoretically and empirically with Hofstede's individualism index. However, the GLOBE project improved on Hofstede's methodology in at 
least three ways: (1) the content of their measures was theoretically driven, and scale items were extensively validated across cultures; (2) the data are more recent, accounting for cultural change in the intervening years; and (3) the measures were derived in a more statistically defensible manner (see Javidan, House, Dorfman, Hanges, \& de Luque, 2006). Thus, although the GLOBE project is less well-known among social psychologists than Hofstede's work, we believe that the GLOBE scores for in-group collectivism practices provide a better archival index of national differences in individualism-collectivism.

Archival measures are useful for sample selection purposes, but they do not substitute for direct measurement of cultural orientations. Particular samples may not be representative of the broader trend of cultural differences between two or more nations, and so it is important to measure differences between the actual groups sampled on the cultural dimension of interest (Smith et al., 2006). Moreover, cultural orientations can be measured at more than one level of analysis. On one level, they are properties of particular social contexts (organizations, regions, ethnicities, nations) and, thus, should be measured ideally at a contextual level of analysis (see Hofstede, 1980). However, it is to be expected also that individuals will differ in the extent to which they internalize any given cultural orientation. If individual- and group-level effects are modeled together, then it becomes possible to distinguish the effects of internalizing a particular cultural orientation oneself from the effects of living in a particular cultural context (e.g., Gheorghiu, Vignoles, \& Smith, 2009).

When measuring individualism-collectivism, it is important to recognize that this broad dimension encompasses a complex assortment of more specific differences in domains such as values, beliefs, norms, attitudes, and behaviors, which cluster together only moderately on a cultural level of analysis and hardly at all on an individual level of analysis (see Owe et al., in press). Given that not all of these characteristics will be shared in equal measure by every individualistic or collectivistic culture, Brewer and Chen (2007) have argued that it is preferable to measure different facets of individualism-collectivism separately rather than relying on the very broad and often unreliable measures that have more commonly been used. In the current study, we focused our measurement on two psychological domains that we considered to be especially crucial aspects of the broader distinction between individualism and collectivism: social values and beliefs about personhood.

In common with many cross-cultural psychologists, Schwartz (1992, 2004) has argued that studying values is an especially efficient way to capture and characterize cultural variation (see also Chinese Culture Connection, 1987; Hofstede, 1980; Smith \& Schwartz, 1997). Based on an extensive cross-cultural study of value priorities, Schwartz (1992) concluded that individual differences in value priorities are organized in a circumplex structure, which can be represented in terms of two bipolar dimensions of openness to change versus conservation and self-enhancement versus self-transcendence. This structure has been found in more than 75 nations, and a similar (but not identical) structure can be used to capture cross-national differences in values (Schwartz, 2004). On this contextual level of analysis, the individual-level distinction between openness and conservation values is largely recaptured in a conceptually similar nation-level dimension that Schwartz (2004) has labeled autonomy versus embeddedness (see also Fischer, 2011; Fischer, Vauclair, Fontaine, \& Schwartz, 2010). Crucially, both the individual-level and the nation-level dimensions contrast value priorities of self-direction and stimulation - thought to be typical of individualistic cultures-with those of tradition, security, and conformity-thought to be typical of collectivistic cultures (Welzel, 2010). Gheorghiu et al. (2009) found that scores on this dimension derived from representative samples in 21 nations converged very closely with Hofstede's (1980) individualism index and with the GLOBE project's scores for in-group collectivism. Nevertheless, Knafo, Schwartz, and Levine (2009) reported that autonomy-embeddedness scores have greater predictive value than global individualism-collectivism, probably reflecting their greater theoretical precision.

In recent years, Bond and Leung (Bond et al., 2004; Leung et al., 2002) have argued that, notwithstanding the importance of cultural differences in values, it is also highly important to examine the nature and consequences of differences in beliefs across cultures. Owe et al. (in press) recently developed a targeted measure to tap into the beliefs about personhood thought to underlie individualistic and collectivistic ways of thinking. Following research and theory suggesting that members of individualistic cultures are prone to adopt a "de-contextualized" view of personhood compared to members of collectivistic cultures (e.g., Miller, 1984; Shweder \& Bourne, 1984; Triandis, Chan, Bhawuk, Iwao, \& Sinha, 1995), they devised a new measure of contextualism beliefs. This measure showed an equivalent factor structure across 19 nations and between individual and national levels of analysis, indicating that the dimension of contextualism beliefs could be used validly to characterize both individuals and national groups. National scores on this measure converged with archival indices of national individualism-collectivism and predicted incremental variance in national differences in several theoretically relevant outcomes (corruption, in-group favoritism, and differential trust of in-group and out-group members) after accounting for the contribution of autonomy-embeddedness values. Thus, it seems that autonomy-embeddedness values and contextualism beliefs are distinct and complementary facets within the broader construct of individualism-collectivism.

A further issue that requires consideration is the relationship between individualism-collectivism and national economic wealth. Because cultural individualism is strongly correlated with economic development (Hofstede, 2001; Weber, 1905/1958), it may be useful to measure these dimensions together so as to distinguish their effects (Smith, 2004b). However, there is little or no consensus currently about how best to treat this issue in statistical analyses. For example, Hofstede $(1980,2006)$ has proposed that one should partial out affluence when looking at the correlates of national individualism, whereas Javidan et al. (2006) have argued that to do so may be removing meaningful cultural variance, because economic development could be a consequence as well as a cause of individualism.

\section{Research Aims}

Extending previous research by Vignoles et al. (2006) on identity motives and on the motive for distinctiveness in particular (Eriksson et al., 2011; Vignoles, Chryssochoou, \& Breakwell, 2002), the central purpose of the current study was to examine how the operation of the distinctiveness motive can be influenced by 
the cultural context surrounding the person. Our study was conducted among participants in 21 cultural groups, spanning 19 nations across four continents.

We measured the strength of the distinctiveness motive using an extended and culturally decentered version of the methodology of Vignoles and Moncaster (2007). In addition to modeling withinparticipant relationships between the distinctiveness and perceived centrality of identity aspects, we also modeled the relationships between distinctiveness and the positive affective valence of identity aspects. We should acknowledge that Vignoles et al. (2006) did not find a positive relationship between distinctiveness and positive affect on average across their Western European participants; however, our main focus in the current study was on individual and cultural differences in this relationship, not on its mean level. We reasoned that participants with a stronger motive for distinctiveness would show a relatively stronger tendency to be more happy about those aspects of their identities that distinguished them more from others and less happy about those aspects of their identities that distinguished them less from others; in contrast, those with a weaker motive for distinctiveness would show a weaker tendency, or perhaps even the reverse. Thus, within-participant relationships of distinctiveness with perceived centrality and of distinctiveness with positive affect would serve as two separate indicators of differences in the strength of the motive for distinctiveness. We expected that, on average, participants would be motivated to achieve a sense of distinctiveness within their identities and, thus, that they would perceive as more central to their identities, and be happier about, those identity aspects that are associated more strongly with a general sense of distinctiveness.

Our first main aim was to investigate whether the strength of the distinctiveness motive, measured in these two ways, is moderated by culture. As discussed above, we estimated cultural orientation toward individualism-collectivism by measuring two different aspects of culture-autonomy-embeddedness values and contextualism beliefs-to establish whether our findings were sufficiently robust to generalize across these alternative measures. Hence, we tested the effects of cultural values and beliefs on the strength of the motive for distinctiveness in separate, parallel analyses. Moderation of the strength of within-participant relationships between distinctiveness and perceived centrality or between distinctiveness and positive affect by these measures of cultural orientation would indicate that the strength of the distinctiveness motive varies by culture, whereas the absence of moderation effects would signify that the motive is independent of these values and beliefs. Given the lack of consensus in the literature about how best to treat the relationship between individualism-collectivism and national affluence, we opted for the more conservative route of controlling for affluence; however, we also conducted parallel analyses that do not control for affluence (reported in Footnotes 5-10). Additionally, to control for the possibility that our samples might be differentially affluent within their respective nations, we included and controlled for an individual-level self-report measure of socioeconomic status.

Three competing predictions were tested, derived from the literature reviewed above. From a relativist perspective (e.g., Triandis, 1995), it has been proposed that the motive for distinctiveness will be stronger among individuals in more individualistic cultures (Hypothesis 1 [H1]), on the basis that individualistic cultures portray distinctiveness as a desirable attribute. In direct contrast, from a universalist perspective, Brewer and Roccas (2001) have proposed that the motive will be stronger among individuals in more collectivist cultures (Hypothesis 2 [H2]), on the basis that collectivistic cultures will provide fewer opportunities to satisfy this motive, leading to frustration and hence to greater arousal of the motive. Our own perspective (e.g., Vignoles et al., 2000) suggests that the strength of the motive for distinctiveness should be relatively similar across individualistic and collectivistic cultures (Hypothesis 3 [H3]) because the motive is understood to be universal, and because different cultural systems are understood to provide different—but equally viable-ways of satisfying the motive.

Our second main aim was to clarify whether distinctiveness is achieved in different ways, depending on cultural context, testing Vignoles et al.'s (2000; Vignoles, 2009) predictions regarding sources of distinctiveness. Consistent with previous research in the United Kingdom (Vignoles et al., 2002), we expected that participants would perceive as providing a greater sense of distinctiveness those identity aspects that made them feel different or separate from others or that gave them a specific social position. Crucially, we examined whether cultural orientation toward individualism-collectivism would moderate the extent to which individuals used difference, separateness, or social position as sources of distinctiveness, again controlling for effects of individual and national wealth. Across cultures, we expected to observe that distinctiveness is constructed in different ways, depending on cultural orientations toward individualism-collectivism. More precisely, as we have discussed above, the importance of difference and separateness as sources of distinctiveness was expected to be stronger among individuals in more individualistic cultures (Hypothesis 4 [H4], Hypothesis 5 [H5]). The importance of social position as a source of distinctiveness was expected to be stronger among individuals in less individualistic cultures (Hypothesis 6 [H6]).

We had no strong a priori expectations regarding whether the hypothesized moderation effects would be found at the cultural or at the individual level-in other words, whether or not these differences would be dependent on individuals' personal internalization of the relevant cultural beliefs and values; nevertheless, our multilevel design allowed us to explore this question by differentiating between effects of individual differences and effects of living in a given cultural context. We return to this issue in the discussion.

\section{Method}

\section{Participants and Procedure}

A total of 5,254 late adolescents in 21 cultural groups participated in the study. Ninety-six individuals were excluded because they reported having lived less than 10 years in the country or being 25 years of age or more, thus leaving a sample of 5,158 . (Individual-level sample sizes are slightly lower in our analyses because of missing data on some variables.) The mean age of the overall sample was 16.74 years, and $55 \%$ of participants were female (additional descriptive data, including sample size, gender, and age distribution for each sample, can be found in Table 1). In most cases, each cultural sample was from a different nation. 
Table 1

Descriptive Statistics for Each Cultural Sample

\begin{tabular}{|c|c|c|c|c|c|c|c|c|}
\hline Sample & $N$ & $\%$ female & $M$ age & $\begin{array}{l}M \text { subjective } \\
\text { wealth }\end{array}$ & $\begin{array}{l}M \text { openness to change } \\
\text { (vs. conservation) values }\end{array}$ & $\begin{array}{l}M \text { contextualism } \\
\text { beliefs }\end{array}$ & $\begin{array}{l}\text { GNI per } \\
\text { capita }\end{array}$ & $\begin{array}{l}\text { Questionnaire } \\
\text { language }\end{array}$ \\
\hline Belgium & 246 & 68 & 17.33 & 4.05 & 1.20 & -.46 & 41,110 & French \\
\hline Brazil, Belem, Rio de Janeiro, João Pessoa & 400 & 62 & 16.69 & 3.77 & 1.11 & -.24 & 5,860 & Portuguese \\
\hline Brazil, Goiânia & 123 & 49 & 14.85 & 3.66 & 0.68 & .03 & 5,860 & Portuguese \\
\hline Brazil, Porto Alegre & 210 & 65 & 16.95 & 4.10 & 1.44 & -.49 & 5,860 & Portuguese \\
\hline Chile & 394 & 47 & 16.21 & 4.65 & 0.97 & -.77 & 8,190 & Spanish \\
\hline China & 227 & 48 & 15.88 & 3.58 & 0.46 & -.56 & 2,370 & Chinese \\
\hline Colombia & 203 & 43 & 15.84 & 4.40 & 1.27 & -.59 & 4,100 & Spanish \\
\hline Estonia & 234 & 59 & 16.86 & 4.35 & 1.23 & -.14 & 12,830 & Estonian \\
\hline Ethiopia & 249 & 45 & 17.57 & 3.62 & 0.17 & .12 & 220 & Amharic \\
\hline Georgia & 246 & 58 & 16.11 & 4.27 & 0.67 & -.58 & 2,120 & Georgian \\
\hline Hungary & 238 & 52 & 16.49 & 4.45 & 1.23 & -.73 & 11,680 & Hungarian \\
\hline Italy & 318 & 52 & 17.75 & 4.24 & 0.49 & -.31 & 33,490 & Italian \\
\hline Lebanon & 295 & 46 & 17.07 & 4.55 & 0.67 & -.41 & 5,800 & Arabic \\
\hline Namibia & 96 & 64 & 17.30 & 3.45 & 0.14 & -.75 & 3,450 & English \\
\hline Oman & 248 & 49 & 16.51 & 4.83 & 0.07 & -.27 & 12,860 & Arabic \\
\hline Philippines & 296 & 66 & 17.38 & 4.23 & 0.14 & .41 & 1,620 & English \\
\hline Poland & 249 & 57 & 17.24 & 4.54 & 0.97 & -.64 & 9,850 & Polish \\
\hline Romania & 220 & 49 & 17.08 & 4.79 & 0.74 & -.51 & 6,390 & Romanian \\
\hline Spain & 223 & 53 & 16.44 & 4.59 & 1.19 & -.72 & 29,290 & Spanish \\
\hline Turkey & 197 & 50 & 16.52 & 4.10 & 0.19 & -.10 & 8,030 & Turkish \\
\hline United Kingdom & 246 & 76 & 16.66 & 4.20 & 1.24 & -.68 & 40,660 & English \\
\hline Total & 5,158 & 55 & 16.74 & 4.25 & 0.79 & -.40 & & \\
\hline
\end{tabular}

Note. GNI per capita $=$ gross national income per capita in U.S. dollars

However, given the size and diversity of Brazil, regional samples from five different sites were included from this nation. Based on initial analyses, we distinguished three cultural profiles within the Brazilian data: The most individualistic profile was found among participants from Porto Alegre (Southern coastal region), whereas the participants from Belem (Northern inland region), Rio de Janeiro, and João Pessoa (Southeastern and Northeastern coastal regions) showed an intermediate profile, and the participants from Goiânia (Central, inland region) showed a more collectivistic profile. ${ }^{1}$ The data were divided according to these distinctions in cultural orientation, and three Brazilian cultural groups were used in all subsequent analyses. All participants were students in high schools or equivalent, except in the Philippines, where, to match the age range of participants from other nations, it was necessary to sample university students. The participation of mainly high school students means that the samples are likely to have been somewhat more representative of their respective cultures than would have been the case had university or college students been sampled, given that overall participation rates are higher for upper secondary than for tertiary education (United Nations Educational, Scientific and Cultural Organization, 2010). Participants were recruited voluntarily at their schools and were not compensated in any way. In nations where this was an ethical requirement, parental consent was obtained in advance. Participants were told that the questionnaire formed part of a university project on beliefs, thoughts, and feelings; however, they remained uninformed about the specific purpose of the research and about its cross-cultural character. Administration of the questionnaire was usually in smaller groups or whole classes, although individual administration was used for cultural groups where the local research team thought this was necessary.

\section{Measures}

Measures were included within a larger questionnaire concerning identity construction and cultural orientation. Only the measures relevant to this article are described here. The questionnaires were translated from English into the main language of each country, indicated in Table 1. Independent back-translations were made by bilinguals who were not familiar with the research topic and hypotheses. Ambiguities and inconsistencies were identified and resolved by discussion, adjusting the translations where necessary.

Generation of identity aspects. First, participants were asked to freely generate 10 answers to the question "Who are you?" (hereafter, these answers are referred to as identity aspects), using an adapted version of the Twenty Statements Test (TST; Kuhn \& McPartland, 1954). This part of the questionnaire was located at the very beginning of the questionnaire, so that responses would be constrained as little as possible by theoretical expectations or demand characteristics. It was printed on a page that folded out to the side of the main answer booklet, so that participants could see their identity aspects during the ratings that followed.

Previous studies using the TST methodology to access identity content have sometimes been criticized for priming an individualized, decontextualized, introspective "self" that may be closer to

\footnotetext{
${ }^{1}$ These three groups differed both on openness (vs. conservation) values, $F(2,711)=14.97, p<.001, \eta^{2}=.04$, and contextualism beliefs, $F(2$, 711) $=9.83, p<.001, \eta^{2}=.03$. All pairwise comparisons indicated significant differences $(p s \leq .026)$. Descriptives for these samples on the cultural orientation variables are provided in Table 1.
} 
Western than to other cultural conceptions of self-hood (see Smith, 2011). To achieve a culturally decentered version of this task, we held extensive discussions with study collaborators. As a result, we reworded the original question "Who am I?" into "Who are you?" We also developed a new, decentered version of the instructions following this question:

In the numbered spaces below, please write down 10 things about yourself. You can write your answers as they occur to you without worrying about the order, but together they should summarize the image you have of who you are. Your answers might include social groups or categories you belong to, personal relationships with others, as well as characteristics of yourself as an individual. Some may be things that other people know about, others may be your private thoughts about yourself. Some things you may see as relatively important, and others less so. Some may be things you are relatively happy about, and others less so.

We indeed found individual characteristics (e.g., "sociable," "intelligent," "shy"), social roles, and interpersonal relationships (e.g., "friend," "son," "pupil") as well as social categories (e.g., "girl," "human being," "British") among common answers.

Ratings of identity aspects. Participants were then asked to rate each of their identity aspects on a number of different dimensions. Each dimension was presented as a question at the top of a new page, with a block of 11-point scales positioned underneath to line up with the identity aspects. Two questions were included to tap the cognitive and affective dimensions of identity construction, respectively. A first question measured the perceived centrality of each identity aspect within participants' subjective identity structures ("How important is each of these things in defining who you are?"; scale anchors were $0=$ not at all important, $10=$ extremely important). A second question measured positive affect in relation to each identity aspect ("How happy or unhappy do you feel about each of these things?"; scale anchors were $0=$ extremely unhappy, $10=$ extremely happy).

Four questions measured the association of each identity aspect with feelings of distinctiveness: general distinctiveness ("How much do you feel that each of these things distinguishes you-in any sense-from other people?"; scale anchors were $0=$ not at all, 10 extremely), social position ("How much does each of these things give you a particular role or position in relation to others?'; scale anchors were $0=$ not at all, $10=$ extremely), difference ("How much does each of these things make you a different kind of person from others?"; scale anchors were $0=$ not at all, $10=$ extremely), and separateness ("How much does each of these things create any sort of boundary between yourself and others?"; scale anchors were $0=$ not at all, $10=$ extremely).

To ensure that distinctiveness was not made salient before participants answered the perceived centrality and affect measures, these measures were placed before the measure of distinctiveness, separated by several pages of intervening measures. Similarly, the measures for social position, difference, and separateness were placed after the general distinctiveness item in another section of the questionnaire. These four questions related to distinctiveness were interspersed among 19 other rating questions related to other identity motives (e.g., belonging and self-esteem).

Portrait value questionnaire. We used a short version of this questionnaire, created by Schwartz (2007; see also Schwartz \& Rubel, 2005, Study 1). The 21-item scale incorporates statements presented as short descriptions of a person. Respondents are asked to indicate how much each description is or is not like them. The 6-point response scale ranges from 1 (very much like me) to 6 (not like me at all); however, we reverse-coded all items so that higher scores would reflect greater endorsement of the value portrayed in the item. As recommended by Schwartz and Rubel (2005), we then ipsatized the responses by centering each participant's item scores around his or her mean across all the items (i.e., subtracting the participant's mean on the scale from his or her score on each item) to eliminate individual differences in response style. ${ }^{2}$

These ipsatized scores were used to create a measure of the bipolar value dimension of interest to the present study: openness to change versus conservation values (12 items: overall $\alpha=.69$, $M d n \alpha=.68){ }^{3}$ Sample items for this dimension were as follows: "He/she looks for adventures and likes to take risks. He/she wants to have an exciting life," and "It is important to him/her to always behave properly. He/she wants to avoid doing anything people would say is wrong" (reversed). As described above, nation-level scores from this bipolar dimension can be used as an indicator of individualism-collectivism (Gheorghiu et al., 2009; Welzel, 2010). ${ }^{4}$

Contextualism. This scale, developed by Owe et al. (in press), taps into the beliefs about personhood that are thought to underlie cultural collectivism. It measures beliefs about the importance (vs. unimportance) of social and contextual attributes in defining a person. The scale consists of six balanced items, in-

\footnotetext{
${ }^{2}$ All models presented were also computed with non-ipsatized scores for values and beliefs, and the results were the same. Full details of these analyses are available from the first author on request.

${ }^{3}$ On each of our cultural orientation measures, a number of samples had mediocre individual-level reliabilities. This is a common problem for measures of cultural difference and has been argued to be a foreseeable downside of any measure with sufficient bandwidth among the items to provide validity in a variety of cultures (Singelis, Triandis, Bhawuk, \& Gelfand, 1995). Particularly relevant to the Portrait Value Questionnaire used here, Fontaine, Poortinga, Delbeke, and Schwartz (2008) found that samples from less developed nations deviate more from the theoretical structure of the value model than samples from more developed nations. As a consequence, lower individual-level reliabilities on our measure of openness (vs. conservation) would be expected in samples with lower scores on this same dimension. Of importance here is that even if individual-level reliabilities of our measures of cultural orientation are mediocre in some of the cultural samples, the cultural-level reliabilities are very good (openness [vs. conservation]: $\alpha=.84$; contextualism beliefs: $\alpha=.94)$. Given that our main findings draw on effects situated on this higher level of analysis, poor reliabilities on the individual level do not challenge these findings.

${ }^{4}$ Recent studies of the similarity - or isomorphism-of value structures at an individual and at a nation level have found that, although isomorphism is not perfect, there is substantial similarity in structure between the two levels of analysis (Fischer, 2011; Fischer et al., 2010). The dimension of openness to change versus conservation values presents relatively higher levels of isomorphism, enabling the use of this dimension when comparing both national samples and individuals, especially if researchers are interested in the broader underlying dimension rather than more specific value types (Fischer, 2011). Nevertheless, based on recommendations by S. H. Schwartz (personal communication, March 1, 2011), the presented analyses were also conducted using a shorter scale (omitting two items) for autonomy-embeddedness values (i.e., the culture-level value dimension). The same pattern of results was found using this shorter scale.
} 
cluding, for example, "To understand a person well, it is essential to know about his/her family" and "One can understand a person well without knowing about the place he/she comes from" (reversed). Participants rated their level of agreement with each statement on a 6-point scale ranging from 1 (completely disagree) to 6 (completely agree). As for values, participants' ratings were ipsatized to remove differences in response style (overall $\alpha=.75$, $M d n \alpha=.73$; see Footnote 3). The degree of contextualism was used in our analyses as an indicator of collectivism-individualism.

Demographic information. Participants were asked to indicate their gender, date of birth, nationality, country of birth, and a number of other demographic characteristics. They were also asked to estimate their family's wealth relative to other people living in their nation ("Compared to other people in [nation], how would you describe your family's level of financial wealth?") on a 7-point scale ranging from 1 (very poor) to 7 (very rich). To control for national differences in economic development, we included data on gross national income (GNI) per capita, retrieved from the World Bank (2010) report.

\section{Statistical Analyses}

Given the nested structure of the data, we used multilevel regression analysis (Hox, 2002) to test our hypotheses. All analyses were conducted with HLM 6 (Raudenbush, Bryk, \& Congdon, 2007) using full maximum likelihood estimation with a convergence criterion of .000001 . Rather than individuals, the primary unit of analysis was identity aspects. Level 1 units were identity aspects $(N=45,406)$, with individuals as Level 2 units $(N=$ $4,751)$, and cultures as Level 3 units $(N=21)$. At Level 1 , regression equations were modeled for within-participant variables (perceived centrality, positive affect, general distinctiveness, difference, separateness, and social position). Predictors on this level were centered around participant means, thus ensuring that the within-participant effects that we were interested in were not confounded with between-participant covariance (Hofmann \& Gavin, 1998; Raudenbush, 1989). At Level 2, regression coefficients were modeled for individual difference variables (gender, subjective wealth, individual value priorities, and individual contextualism). Gender was included to control for differences in the gender composition of our samples, but we had no theoretical basis for predicting gender effects. At Level 3, regression coefficients were modeled for culture-level variables (group mean value priorities, group mean contextualism, and GNI per capita). Continuous variables at Levels 2 and 3 were centered around their grand means, and a dummy code was used for gender (female $=-1$, male $=1$ ). We used grand-mean centering rather than group-mean centering at Level 2 to provide a more accurate test of Level 3 effects within our models, controlling for the potential confounding influence of aggregated individual-level relationships when testing culture-level relationships (Firebaugh, 1980; Hofmann \& Gavin, 1998).

Our main hypotheses involved testing cross-level interactions in which variables at Levels 2 and 3 were allowed to moderate the strengths of relationships observed at Level 1. As discussed by McClelland and Judd (1993), it is notoriously difficult to detect moderation effects in correlational studies, and even substantively important interactions may account for seemingly trivial amounts of variance. Hence, in addition to estimating the proportion of within-participants variance accounted for by our models (calculated as the proportional reduction in the Level 1 error term compared to a null model; Hox, 2002), we have also estimated the magnitude of the Level 1 effects at differing values of our cultural moderators to help readers to evaluate the substantive importance of those interaction effects that relate to our hypotheses (for a similar approach, see Cooper, 2010).

Zero-order correlations for all variables are shown in Appendices A, B, and C. The study included measures of two alternative indicators of cultural individualism-collectivism: openness (vs. conservation) values and contextualism beliefs. As expected, these two measures showed a moderately strong negative correlation at the cultural level $(r=-.49, p=.024)$ and a weak negative correlation at the individual level $(r=-.16, p<.001)$. This provided an opportunity to test the robustness of our findings using competing operational definitions of individualism-collectivism. Consequently, we tested our hypotheses separately with each measure of cultural orientation, and results were compared.

\section{Results}

\section{Strength of the Distinctiveness Motive According to Culture}

To test the strength of the distinctiveness motive across cultures, we computed a series of models predicting the perceived centrality of identity aspects in subjective identity structures as a function of their distinctiveness. Subsequently, we computed a series of parallel models predicting positive affect associated with identity aspects. Parameters of these models are shown in Table 2 (perceived centrality) and Table 3 (positive affect).

Effects of distinctiveness on perceived centrality. In our first model predicting perceived centrality, we included just the general distinctiveness rating as a predictor at Level 1 (Model 1). As expected, across the sample as a whole, distinctiveness was a significant positive predictor of perceived centrality $(B=.33, p<$ .001 ), and this model accounted for an estimated $10.8 \%$ of withinparticipants variance in perceived centrality.

Next, we added cross-level interaction effects to test whether the strength of the distinctiveness motive was significantly moderated by either individual or cultural value priorities, providing our first test among the three competing hypotheses H1-H3. Thus, we entered individual scores of openness (vs. conservation) values, gender, and subjective wealth as Level 2 predictors of the Level 1 weight on distinctiveness, and cultural group means of openness (vs. conservation) values and GNI per capita as Level 3 predictors of the Level 1 weight on distinctiveness, to test for cross-level interactions (Model 2). Following standard procedure for testing interaction effects in multiple regression (Aiken \& West, 1991), we included the underlying main effects in our models alongside the theoretically important interaction effects.

Compared with Model 1, this model was a significant improvement, $\chi^{2}(10)=39.11, p<.001$, but there was no increase in modeled variance at Level 1 . Within this model, significant crosslevel interactions would mean that the weight of general distinctiveness on perceived centrality varied according to individuals' values, cultural mean values, gender, subjective wealth, or GNI per capita. A negative cross-level interaction effect was found for culture-level openness (vs. conservation) $(B=-.02, p=.053)$. 
Table 2

Estimated Parameters of Multilevel Regression Predicting Perceived Centrality

\begin{tabular}{|c|c|c|c|c|c|c|c|c|c|}
\hline \multirow[b]{2}{*}{ Variable } & \multicolumn{3}{|c|}{ Model 1} & \multicolumn{3}{|c|}{ Model 2} & \multicolumn{3}{|c|}{ Model 3} \\
\hline & $B$ & $S E$ & $p$ & $B$ & $S E$ & $p$ & $B$ & $S E$ & $p$ \\
\hline \multicolumn{10}{|c|}{ Within-participants main effect (Level 1: $N=45,406$ identity aspects) } \\
\hline General distinctiveness & .33 & .00 & $<.001$ & .33 & .00 & $<.001$ & .33 & .00 & $<.001$ \\
\hline \multicolumn{10}{|l|}{ Individual-level main effects (Level 2: $N=4,751$ individuals) } \\
\hline Openness (vs. Conservation) & & & & .02 & .01 & .209 & & & \\
\hline Contextualism & & & & & & & .02 & .02 & .267 \\
\hline Gender $^{\mathrm{a}}$ & & & & -.07 & .02 & $<.001$ & -.07 & .02 & $<.001$ \\
\hline Subjective wealth & & & & .04 & .02 & .024 & .04 & .02 & .024 \\
\hline \multicolumn{10}{|l|}{ Culture-level main effects (Level 3: $N=21$ cultural groups) } \\
\hline Openness (vs. Conservation) & & & & -.22 & .15 & .151 & & & \\
\hline Contextualism & & & & & & & .08 & .22 & .705 \\
\hline GNI per capita & & & & -.14 & .05 & .019 & -.16 & .05 & .009 \\
\hline \multicolumn{10}{|l|}{ Individual-level moderators of within-participants slope } \\
\hline Openness (vs. Conservation) $\times$ General Distinctiveness & & & & .00 & .00 & .841 & & & \\
\hline Contextualism $\times$ General Distinctiveness & & & & & & & .00 & .01 & .387 \\
\hline Gender $\times$ General Distinctiveness & & & & .00 & .00 & .795 & .00 & .00 & .884 \\
\hline Subjective Wealth $\times$ General Distinctiveness & & & & .01 & .00 & .194 & .01 & .00 & 169 \\
\hline \multicolumn{10}{|l|}{ Culture-level moderators of within-participants slope } \\
\hline Openness (vs. Conservation) $\times$ General Distinctiveness & & & & -.02 & .01 & .053 & & & \\
\hline Contextualism $\times$ General Distinctiveness & & & & & & & .03 & .02 & 113 \\
\hline GNI per capita $\times$ General Distinctiveness & & & & .00 & .00 & .271 & .00 & .00 & .440 \\
\hline \multicolumn{10}{|l|}{ Residual variance } \\
\hline Within-participant level $\left(\sigma^{2}\right)$ & & 4.38 & & & & 4.38 & & & 4.38 \\
\hline Individual level $\left(\tau_{\pi}\right)$ & & .89 & $<.001$ & & .89 & $<.001$ & & .89 & $<.001$ \\
\hline Culture level $\left(\tau_{\beta}\right)$ & & .12 & $<.001$ & & .07 & $<.001$ & & .08 & $<.001$ \\
\hline Deviance & & 201,096 & & & 01,057 & & & 201,060 & \\
\hline
\end{tabular}

Note. GNI per capita $=$ gross national income per capita in units of 10,000 U.S. dollars.

${ }^{\text {a }}$ Dummy coded as $-1=$ female, $1=$ male.

This signifies that the degree to which an identity aspect provided a sense of distinctiveness had a marginally stronger effect on the perceived centrality of that identity aspect in cultures where openness values were relatively weaker and conservation values were relatively stronger. In other words, the motive for distinctiveness was marginally stronger in more collectivistic cultures. ${ }^{5}$ No significant moderations of the individual-level variables or GNI per capita were found.

To illuminate further the nature of the interaction between culture-level openness (vs. conservation) and distinctiveness, we used a simple slopes technique. The main effect of distinctiveness on centrality was estimated at lower bound (-.10) and higher bound (1.60) values of the moderator. Figure $3 \mathrm{~A}$ illustrates that the effect of distinctiveness was only very slightly stronger in cultures with the lowest openness (vs. conservation) values $(B=.35, p<$ .001) compared to cultures with the highest scores on this dimension $(B=.31, p<.001)$. Thus, the data were very clearly inconsistent with $\mathrm{H} 1$, but they could be interpreted as supporting either $\mathrm{H} 2$ (given the marginal interaction) or $\mathrm{H} 3$ (given that there was only a very small difference in magnitude of the simple slopes across the range of cultural variation in our sample).

We then ran a parallel model replacing openness (vs. conservation) values with contextualism on both the individual and culture levels (Model 3). This model provided a significant improvement over Model 1, $\chi^{2}(10)=35.39, p<.001$, but again there was no increase in modeled variance. No significant moderation effects by contextualism were found, although the estimated coefficient of the cross-level interaction between culture-level contextualism and distinctiveness was again in the direction predicted by $\mathrm{H} 2$ ( $B=$ $.03, p=.113)$. As in the previous model, no significant moderations of the individual-level variables or GNI per capita were found. ${ }^{6}$

We used simple slopes to explore further the relation between culture-level contextualism and distinctiveness. The main effect of distinctiveness on centrality was estimated at relatively low $(-.95)$ and high (.60) values of the moderator. This relation is plotted in Figure 3B. Consistent with H3, the effect of distinctiveness was broadly similar in cultures with the highest contextualism beliefs $(B=.36, p<.001)$ compared to those with the lowest contextualism scores $(B=.32, p<.001)$.

Effects of distinctiveness on positive affect. The same three predictive models were run with positive affect replacing per-

\footnotetext{
${ }^{5}$ A similar size negative estimate for the moderation effect of culturelevel openness (vs. conservation) values was found when controls were included for the second value dimension from Schwartz's $(1992,2004)$ model of human values, self-transcendence (vs. self-enhancement) values, and when not controlling for GNI per capita, subjective wealth, and gender.

${ }^{6}$ The estimate of culture-level contextualism beliefs as a moderator of the slope of distinctiveness on perceived centrality was similar $(B=.02$, $p=.200$ ) when not controlling for GNI per capita, subjective wealth, and gender. An additional model including both openness (vs. conservation) values and contextualism beliefs as moderators resulted in similar estimates, moderation by culture-level openness (vs. conservation) $(B=-.02$, $p=.141)$, and moderation by culture-level contextualism $(B=.01, p=$ $.561)$
} 


\begin{tabular}{|c|c|c|c|c|c|c|c|c|c|}
\hline \multirow[b]{2}{*}{ Variable } & \multicolumn{3}{|c|}{ Model 4} & \multicolumn{3}{|c|}{ Model 5} & \multicolumn{3}{|c|}{ Model 6} \\
\hline & $B$ & $S E$ & $p$ & $B$ & $S E$ & $p$ & $B$ & $S E$ & $p$ \\
\hline \multicolumn{10}{|c|}{ Within-participants main effect (Level 1: $N=45,406$ identity aspects) } \\
\hline General distinctiveness & .31 & .01 & $<.001$ & .31 & .01 & $<.001$ & .31 & .01 & $<.001$ \\
\hline \multicolumn{10}{|l|}{ Individual-level main effects (Level 2: $N=4,751$ individuals) } \\
\hline Openness (vs. Conservation) & & & & .05 & .02 & .007 & & & \\
\hline Contextualism & & & & & & & .03 & .02 & .162 \\
\hline Gender $^{\mathrm{a}}$ & & & & .08 & .02 & $<.001$ & .07 & .02 & $<.001$ \\
\hline Subjective wealth & & & & .08 & .02 & $<.001$ & .08 & .02 & $<.001$ \\
\hline \multicolumn{10}{|l|}{ Culture-level main effects (Level 3: $N=21$ cultural groups) } \\
\hline Openness (vs. Conservation) & & & & -.23 & .12 & .079 & & & \\
\hline Contextualism & & & & & & & .10 & .18 & .592 \\
\hline GNI per capita & & & & -.14 & .04 & .006 & -.15 & .04 & .003 \\
\hline \multicolumn{10}{|l|}{ Individual-level moderators of within-participants slope } \\
\hline Openness (vs. Conservation) $\times$ General Distinctiveness & & & & .01 & .00 & .019 & & & \\
\hline Contextualism $\times$ General Distinctiveness & & & & & & & .00 & .01 & .950 \\
\hline Gender $\times$ General Distinctiveness & & & & -.01 & .01 & .022 & -.01 & .01 & .026 \\
\hline Subjective Wealth $\times$ General Distinctiveness & & & & .02 & .01 & .003 & .02 & .01 & .001 \\
\hline \multicolumn{10}{|l|}{ Culture-level moderators of within-participants slope } \\
\hline Openness (vs. Conservation) $\times$ General Distinctiveness & & & & -.10 & .01 & $<.001$ & & & \\
\hline Contextualism $\times$ General Distinctiveness & & & & & & & .06 & .02 & .005 \\
\hline GNI per capita $\times$ General Distinctiveness & & & & -.02 & .00 & $<.001$ & -.03 & .00 & $<.001$ \\
\hline \multicolumn{10}{|l|}{ Residual variance } \\
\hline Within-participant level $\left(\sigma^{2}\right)$ & & 6.22 & & & 6.21 & & & 6.21 & \\
\hline Individual level $\left(\tau_{\pi}\right)$ & & 1.20 & $<.001$ & & 1.18 & $<.001$ & & 1.18 & $<.001$ \\
\hline Culture level $\left(\tau_{\beta}\right)$ & & .09 & $<.001$ & & .04 & $<.001$ & & .04 & $<.001$ \\
\hline Deviance & & 216,838 & & & 216,685 & & & 216,732 & \\
\hline
\end{tabular}

Note. GNI per capita $=$ gross national income per capita in units of 10,000 U.S. dollars.

${ }^{\text {a }}$ Dummy coded as $-1=$ female, $1=$ male.

ceived centrality as the outcome variable. The first model included just the general distinctiveness rating as a predictor at Level 1 (Model 4). Across the sample as a whole, distinctiveness was a significant positive predictor of positive affect $(B=.31, p<.001)$, and this model accounted for an estimated $6.9 \%$ of withinparticipants variance in positive affect.

Next, we added cross-level interaction effects to test whether the strength of the distinctiveness motive was significantly moderated by either individual or cultural value priorities (Model 5). Again, all main effects were also included. Compared with Model 4 , this model was a significant improvement, $\chi^{2}(10)=153.44, p<.001$, and the amount of modeled Level 1 variance increased very slightly to $7.0 \%$. Consistent with $\mathrm{H} 2$, a negative cross-level interaction effect was found for culture-level openness (vs. conservation) $(B=-.10, p<.001)$. This signifies that the degree to which an identity aspect provided a sense of distinctiveness was more closely associated with feelings of positive affect in cultures with weaker openness values and stronger conservation values. In other words, the motive for distinctiveness was significantly stronger in more collectivistic cultures. ${ }^{7}$ In addition, there was a negative interaction effect of GNI per capita $(B=-.02, p<.001)$, indicating that the effect of general distinctiveness on positive affect is stronger in poorer nations. Simple slopes were used to probe the interaction between culture-level openness (vs. conservation) values and distinctiveness. This interaction is plotted in Figure 3A. Supporting H2, the effect of distinctiveness was more than $70 \%$ stronger in cultures with the lowest scores for openness (vs. conservation) values $(B=.40, p<.001)$ compared to those with the highest scores on this dimension $(B=.23, p<.001)$.
Within Model 5, all three individual-level moderators were also significant, although effects were very small in magnitude: gender $(B=-.01, p=.022)$, subjective wealth $(B=.02, p=.003)$, and individual-level openness (vs. conservation) $(B=.01, p=.019)$. These interactions indicate that distinctiveness had a slightly stronger effect on positive affect among women, among participants from richer families within their respective nations, and among individuals with stronger openness (vs. conservation) values. Given its relevance to our hypotheses, we used the simple slopes technique to estimate the main effect of distinctiveness on affect at the maximum (3.30) and minimum $(-1.70)$ observed values of individual-level openness (vs. conservation). The effect of distinctiveness was somewhat stronger at the maximum score for openness (vs. conservation) values $(B=.35, p<.001)$ compared to the minimum score $(B=.25, p<.001)$. This provides modest support for $\mathrm{H} 1$ at the individual level, in contrast with the culture-level moderation that supported $\mathrm{H} 2$.

We then ran a parallel model replacing openness (vs. conservation) values with contextualism on both the individual and culture levels (Model 6). This model provided a significant improvement over Model $4, \chi^{2}(10)=106.40, p<.001$, and the amount of modeled variance increased very slightly to $7.0 \%$. Supporting H2,

\footnotetext{
${ }^{7}$ Similar estimates for the moderation effect of culture-level openness (vs. conservation) values were found when controls were included for the second value dimension from Schwartz's $(1992,2004)$ model of human values, self-transcendence (vs. self-enhancement) values, and when not controlling for GNI per capita, subjective wealth, and gender.
} 

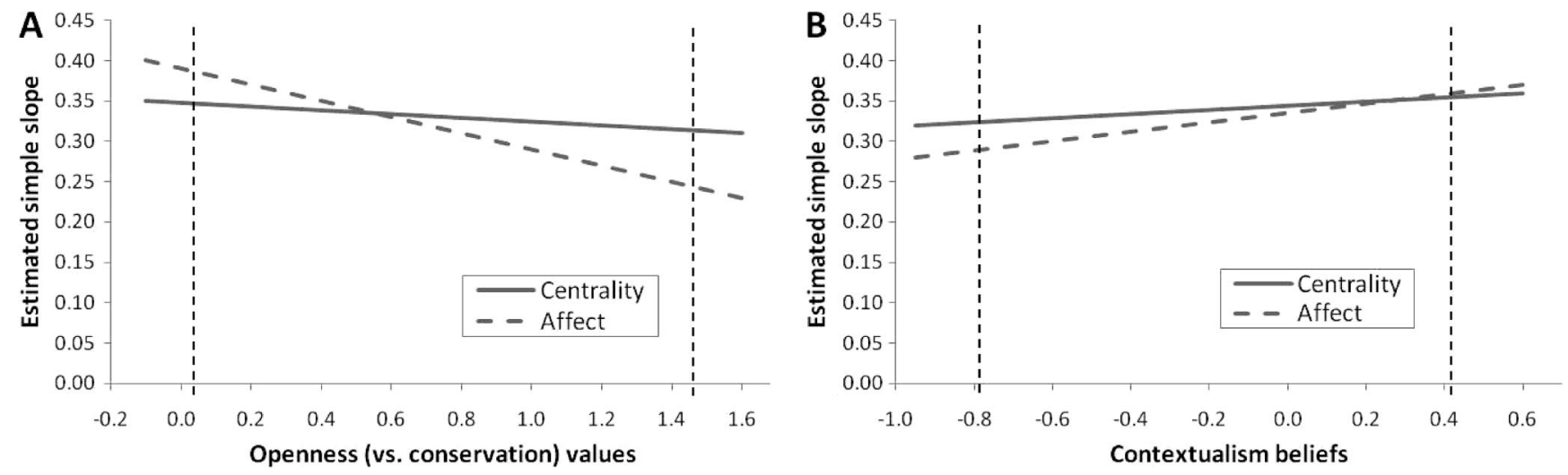

Figure 3. Sense of distinctiveness as a predictor of perceived identity centrality and positive identity affect, depending on values (Panel A) and beliefs (Panel B) in participants' cultural environment. Vertical dotted lines represent observed minimum and maximum values for openness (vs. conservation) values and contextualism beliefs, respectively.

a positive cross-level interaction effect was found for culture-level contextualism $(B=.06, p=.005)$, indicating again that the motive for distinctiveness was stronger in more collectivistic cultures. Moderations by GNI per capita, gender, and subjective wealth were consistent as found in Model 5. However, no individual-level moderation by contextualism beliefs was found. Simple slopes were used to probe the interaction between culture-level contextualism and distinctiveness. This interaction is plotted in Figure 3B. Supporting H2, the effect of distinctiveness was over $30 \%$ stronger in cultures with the strongest contextualism beliefs $(B=$ $.37, p<.001)$ compared to those with the weakest contextualism beliefs $(B=.28, p<.001){ }^{8}$

\section{Sources of Distinctiveness Satisfaction According to Culture}

To test for cultural differences in the construction of distinctiveness, we next computed multilevel regression models predicting general distinctiveness ratings using the three different sources of distinctiveness: difference, separateness, and social position. Parameters of these models are shown in Table 4. Model 7 included just these three ratings as Level 1 predictors of the general distinctiveness ratings. As hypothesized, all three sources of distinctiveness were significant predictors of the general distinctiveness ratings ( $B$ s from .07 to .39), indicating that, overall, difference, separateness, and social position can serve as sources of a general feeling of distinctiveness, and this model accounted for an estimated $23.2 \%$ of within-participants variance in distinctiveness.

Next, we tested cross-level interaction effects to see whether the weight of general distinctiveness on each of the three sources was significantly moderated by either individual or cultural values, providing our first test of hypotheses H4-H6. Thus, we entered individual scores of openness (vs. conservation) values, gender, and subjective wealth as Level 2 predictors of the Level 1 weights, and cultural means of openness (vs. conservation) values and GNI per capita as Level 3 predictors of Level 1 weights on the three sources of distinctiveness, again controlling for all underlying main effects (Model 8). Compared to Model 7, this model provided a significant improvement in fit, $\chi^{2}(20)=301.23, p<.001$, and accounted for an estimated $23.8 \%$ of the within-participants variance in distinctiveness ratings. Crucially, we found a pattern of significant cross-level interaction effects consistent with our predictions: Supporting H4 and H5, difference $(B=.05, p<.001)$ and separateness $(B=.04, p<.001)$ were more important in cultures with higher openness (vs. conservation) values; supporting H6, social position was more important in cultures with lower openness (vs. conservation) values $(B=-.06, p<.001)$. Individual-level moderations were also found, although these were much smaller in magnitude; the effect of difference was slightly stronger among participants with stronger openness (vs. conservation) values $(B=.02, p<.001)$, whereas the effect of separateness was slightly stronger among participants with weaker openness (vs. conservation) values $(B=-.02, p<.001)$. Gender $(B=-.02$, $p=.002)$, subjective wealth $(B=.02, p=.001)$, and GNI per capita $(B=.03, p<.001)$ also moderated the weight of general distinctiveness on difference, suggesting that difference was more important among women, among participants from richer families, and among respondents from richer nations. ${ }^{9}$

Simple slopes were used to probe the interaction between culture-level openness (vs. conservation) values and sources of distinctiveness. The main effects of these sources were estimated at relatively low (-.10) and high (1.60) values of the moderator. These interactions are plotted in Figure 4A, which illustrates how the effects of difference and separateness were clearly stronger in

\footnotetext{
${ }^{8}$ The estimate of culture-level contextualism beliefs as a moderator of the slope of distinctiveness on positive affect was similar $(B=.08, p<$ .001) when not controlling for GNI per capita, subjective wealth, and gender. An additional model including both openness (vs. conservation) values and contextualism beliefs as moderators resulted in a similar estimate for the moderation by culture-level openness (vs. conservation) $(B=$ $-.10, p<.001)$. However, the moderation by culture-level contextualism was no longer significant $(B=-.01, p=.638)$.

${ }^{9}$ The same pattern of results was found when controls were included for the second value dimension from Schwartz's $(1992,2004)$ model of human values, self-transcendence (vs. self-enhancement) values, and when not controlling for GNI per capita, subjective wealth, and gender.
} 
Table 4

Estimated Parameters of Multilevel Regression Predicting General Distinctiveness Ratings

\begin{tabular}{|c|c|c|c|c|c|c|c|c|c|}
\hline \multirow[b]{2}{*}{ Variable } & \multicolumn{3}{|c|}{ Model 7} & \multicolumn{3}{|c|}{ Model 8} & \multicolumn{3}{|c|}{ Model 9} \\
\hline & $B$ & $S E$ & $p$ & $B$ & $S E$ & $p$ & $B$ & $S E$ & $p$ \\
\hline \multicolumn{10}{|c|}{ Within-participants main effects (Level 1: $N=45,406$ identity aspects) } \\
\hline Difference & .39 & .01 & $<.001$ & .38 & .01 & $<.001$ & .38 & .01 & $<.001$ \\
\hline Separateness & .07 & .00 & $<.001$ & .07 & .00 & $<.001$ & .08 & .00 & $<.001$ \\
\hline Social position & .14 & .00 & $<.001$ & .14 & .00 & $<.001$ & .14 & .00 & $<.001$ \\
\hline \multicolumn{10}{|c|}{ Individual-level main effects (Level 2: $N=4,751$ individuals) } \\
\hline Openness (vs. Conservation) & & & & .04 & .02 & .038 & & & \\
\hline Contextualism & & & & & & & .03 & .02 & .204 \\
\hline Gender $^{\mathrm{a}}$ & & & & -.03 & .02 & .134 & -.04 & .02 & .098 \\
\hline Subjective wealth & & & & .03 & .02 & .232 & .03 & .02 & .211 \\
\hline \multicolumn{10}{|c|}{ Culture-level main effects (Level 3: $N=21$ cultural groups) } \\
\hline Openness (vs. Conservation) & & & & -.51 & .22 & .036 & & & \\
\hline Contextualism & & & & & & & .46 & .33 & .177 \\
\hline GNI per capita & & & & -.19 & .08 & .029 & -.22 & .08 & .015 \\
\hline \multicolumn{10}{|c|}{ Individual-level moderators of within-participants slopes } \\
\hline Openness (vs. Conservation) $\times$ Difference & & & & .02 & .00 & $<.001$ & & & \\
\hline Openness (vs. Conservation) $\times$ Separateness & & & & -.02 & .00 & $<.001$ & & & \\
\hline Openness (vs. Conservation) $\times$ Social Position & & & & .00 & .00 & .411 & & & \\
\hline Contextualism $\times$ Difference & & & & & & & .00 & .01 & .863 \\
\hline Contextualism $\times$ Separateness & & & & & & & .00 & .00 & .772 \\
\hline Contextualism $\times$ Social Position & & & & & & & -.01 & .00 & .181 \\
\hline Gender $\times$ Difference & & & & -.02 & .01 & .002 & -.02 & .01 & .001 \\
\hline Gender $\times$ Separateness & & & & .00 & .00 & .264 & .01 & .00 & .192 \\
\hline Gender $\times$ Social Position & & & & .00 & .00 & .862 & .00 & .00 & .813 \\
\hline Subjective Wealth $\times$ Difference & & & & .02 & .01 & .001 & .02 & .01 & $<.001$ \\
\hline Subjective Wealth $\times$ Separateness & & & & .00 & .00 & .746 & .00 & .00 & .891 \\
\hline Subjective Wealth $\times$ Social Position & & & & .00 & .00 & .653 & .00 & .00 & .718 \\
\hline \multicolumn{10}{|l|}{ Culture-level moderators of within-participants slopes } \\
\hline Openness $($ vs. Conservation) $\times$ Difference & & & & .05 & .01 & $<.001$ & & & \\
\hline Openness (vs. Conservation) $\times$ Separateness & & & & .04 & .01 & $<.001$ & & & \\
\hline Openness (vs. Conservation) $\times$ Social Position & & & & -.06 & .01 & $<.001$ & & & \\
\hline Contextualism $\times$ Difference & & & & & & & -.08 & .02 & $<.001$ \\
\hline Contextualism $\times$ Separateness & & & & & & & -.01 & .01 & .618 \\
\hline Contextualism $\times$ Social Position & & & & & & & .05 & .02 & .005 \\
\hline GNI per capita $\times$ Difference & & & & .03 & .00 & $<.001$ & .03 & .00 & $<.001$ \\
\hline GNI per capita $\times$ Separateness & & & & .01 & .00 & .123 & .01 & .00 & .039 \\
\hline GNI per capita $\times$ Social Position & & & & .00 & .00 & .449 & .00 & .00 & .804 \\
\hline \multicolumn{10}{|l|}{ Residual variance } \\
\hline Within-participant level $\left(\sigma^{2}\right)$ & & 3.68 & & & 3.65 & & & 3.66 & \\
\hline Individual level $\left(\tau_{\pi}\right)$ & & 1.87 & $<.001$ & & 1.87 & $<.001$ & & 1.87 & $<.001$ \\
\hline Culture level $\left(\tau_{\beta}\right)$ & & .30 & $<.001$ & & .17 & $<.001$ & & .18 & $<.001$ \\
\hline Deviance & & 196,390 & & & 196,089 & & & 196,169 & \\
\hline
\end{tabular}

Note. GNI per capita $=$ gross national income per capita in units of 10,000 U.S. dollars.

${ }^{\mathrm{a}}$ Dummy coded as $-1=$ female, $1=$ male.

cultures with higher openness (vs. conservation) values $(B=.42$, $p<.001$, and $B=.11, p<.001$, respectively) compared to cultures with lower values on this dimension $(B=.34, p<.001$, and $B=.04, p=.001$, respectively). The effect of social position, on the other hand, showed the opposite pattern; it was considerably weaker in cultures with higher openness (vs. conservation) values $(B=.08, p=.001)$ than in cultures with weaker scores on this dimension $(B=.19, p<.001)$.

We subsequently ran a parallel model replacing openness (vs. conservation) values with contextualism on both the individual and culture levels (Model 9). This model provided a significant improvement over Model 7, $\chi^{2}(20)=220.51, p<.001$, and explained an estimated $23.6 \%$ of within-participant variance of the measure of general distinctiveness. Crucially, we found a pattern of cross-level interactions similar to those in the preceding anal- ysis, although not identical. In particular, difference was more important in cultures with lower contextualism beliefs $(B=-.08$, $p<.001$ ) supporting $\mathrm{H} 4$, whereas social position was found to be more important in cultures high on contextualism beliefs $(B=.05$, $p=.005$ ) supporting H6. As in the preceding analysis, the slope of difference was also significantly moderated by gender $(B=$ $-.02, p=.001)$, subjective wealth $(B=.02, p<.001)$, and GNI per capita $(B=.03, p<.001)$, suggesting that distinctiveness was more strongly based on difference among women, among participants from richer families, and in richer nations. Unlike the previous analysis, the slope for separateness was not significantly moderated by contextualism beliefs; thus, H5 was supported when individualism-collectivism was operationalized in terms of values but not in terms of beliefs. However, we did find a moderation effect of GNI per capita $(B=.01, p=.039)$, suggesting that 

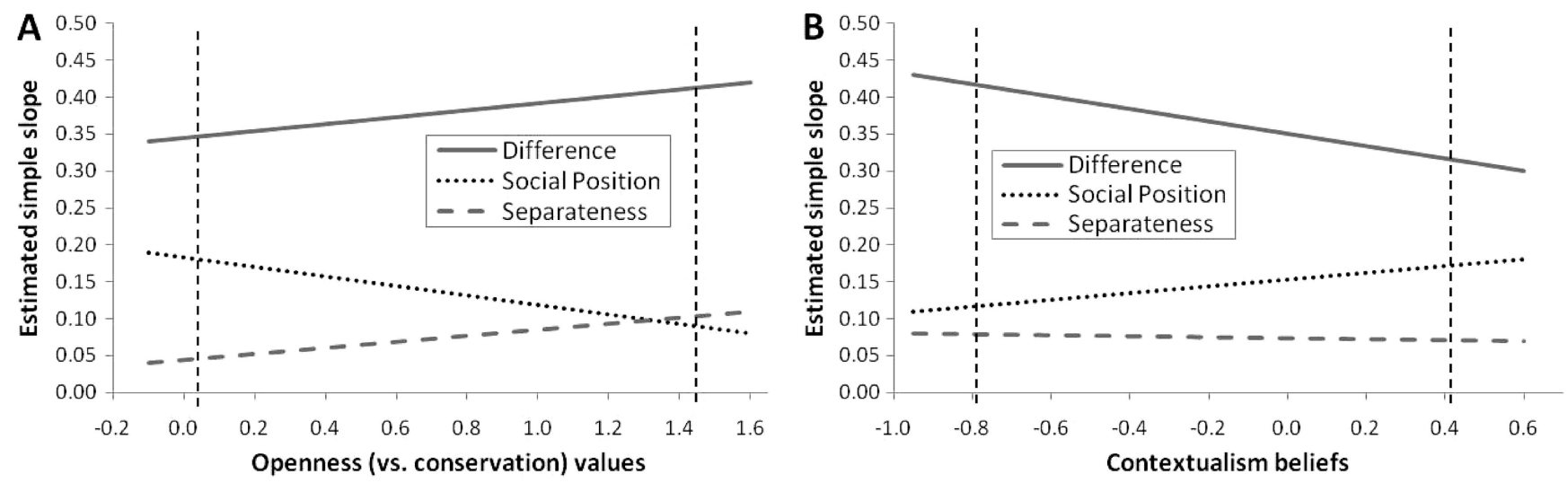

Figure 4. Difference, social position, and separateness as predictors of a general sense of distinctiveness, depending on values (Panel A) and beliefs (Panel B) in participants' cultural environment. Vertical dotted lines represent observed minimum and maximum values for openness (vs. conservation) values and contextualism beliefs, respectively.

distinctiveness was more strongly based on separateness among participants from richer nations. ${ }^{10}$

Main effects of the three sources of distinctiveness were estimated at relatively low (-.95) and high (.60) values of culturelevel contextualism beliefs. These interactions are plotted in Figure $4 \mathrm{~B}$ and show that the effect of social position was clearly stronger in cultures with higher contextualism beliefs $(B=.18, p<.001)$ compared to cultures with weaker contextualism beliefs $(B=.11$, $p<.001)$. The effect of difference, on the other hand, was considerably weaker in cultures with higher contextualism beliefs $(B=.30, p<.001)$ compared to cultures with lower contextualism beliefs $(B=.43, p<.001)$.

\section{Discussion}

\section{Strength of the Distinctiveness Motive Across Cultures}

Participants from 21 cultural groups across four continents generally gave priority in their subjective identity structures to those aspects of their identities that provided them with greater feelings of distinctiveness: In particular, they perceived these identity aspects as more important for their self-definitions and associated them with more positive affect compared to those identity aspects that they perceived as distinguishing them less from others. Consistent with the view that establishing distinctiveness is a precondition for the construction of a coherent sense of identity in any cultural context (Vignoles, 2009; Vignoles et al., 2000), our results suggest that individuals strive for a distinctive identity, whichever cultural meaning system they are surrounded by. Effects of distinctiveness on perceived centrality of identity aspects and on identity-related affect were estimated to be significant at $p<.001$ across the full range of variation in cultural beliefs and values sampled in our study. Hence, even if people are not necessarily aware of it, it seems that distinctiveness-seeking processes generalize robustly to cultural contexts well beyond the Western European and North American contexts where the majority of previous studies into distinctiveness-seeking have been conducted (reviewed by Lynn \& Snyder, 2002; Vignoles, 2009).
Unlike most previous studies into culture and distinctiveness seeking, our approach to measuring the distinctiveness motive here did not rely on explicit measures of self-reported NFU. Instead, we used a more subtle approach to measuring this motive, tapping into the influence of distinctiveness-seeking on identity construction and the affective importance of distinctiveness within identity. Vignoles $(2009,2011)$ has argued that explicit measures are more likely to reflect the extent to which individuals value particular identity states such as distinctiveness (or uniqueness) rather than the strength of their underlying motives. Thus, Eriksson et al. (2011) showed differences between samples of British and Swedish participants on an explicit scale of NFU—which were partially accounted for by differences in value priorities - but participants in both samples tended to prioritize to a similar extent those aspects of their identities that provided a greater sense of distinctiveness. Our results add to this, showing that the underlying motive to attain a distinctive identity is relevant across a much larger range of cultural contexts. ${ }^{11}$

Nevertheless, we did find some evidence that the strength of the distinctiveness motive varied meaningfully with cultural orientation. At the individual level of analysis, there was a slight tendency

\footnotetext{
${ }^{10}$ The same pattern of effects of contextualism was found when not controlling for GNI per capita, subjective wealth, and gender. An additional model including both openness (vs. conservation) values and contextualism beliefs as moderators resulted in similar moderations of the slope for difference (culture-level openness [vs. conservation], $B=.03$, $p=.020$; culture-level contextualism, $B=-.05, p=.026)$ and separateness (culture-level openness [vs. conservation], $B=.04, p=.001$; culturelevel contextualism, $B=.01, p=.574)$. However, only the moderation by values remained significant for the slope of social position (culture-level openness [vs. conservation], $B=-.06, p<.001$; culture-level contextualism, $B=.00, p=.912$ ).

${ }^{11}$ Indeed, consistent with the findings of Eriksson et al. (2011), we note that the same conclusions would not have been drawn had we tested the present hypotheses with a direct measure. As part of a later stage of our study, a subset of respondents $(N=3,272$, from 18 of the 21 cultural groups) also completed the Self-Attributed Need for Uniqueness scale
} 
for those individuals with relatively stronger openness (vs. conservation) values within their respective cultural groups to show a stronger relationship between distinctiveness and positive affect. This provides qualified support for Triandis's (1995) proposal (H1; see also Kim \& Markus, 1999), in that the affective importance of distinctiveness appeared to be stronger among individuals_-but not among cultures-with more individualistic values. ${ }^{12}$ However, this effect was not especially large, and we found no corresponding effect on the importance of distinctiveness in identity construction or when cultural orientation was measured in terms of beliefs rather than values.

More crucially, we found no such effect at the cultural level of analysis. At this level, contrary to $\mathrm{H} 1$, the distinctiveness motive appeared to be stronger among members of collectivistic rather than individualistic cultures (H2; after Brewer \& Roccas, 2001). Although the effect sizes were still relatively small, the trend was in the same direction across all four tests that we conductedpredicting both perceived centrality and identity-related affect, and with both operational definitions of individualism-collectivismand it reached at least marginal significance in three out of four tests. This clearly contradicts the prevailing relativist view on how culture influences identity motives - the idea that identity motives are internalized manifestations of cultural beliefs and values (Breakwell, 1987; Heine, Lehman, Markus, \& Kitayama, 1999; Triandis, 1995). Instead, these results arguably add support to an "oppositional view," proposing that individuals develop stronger motives for those needs that their cultural environment fails to satisfy (Brewer \& Roccas, 2001; Lo et al., 2011). Our evidence suggests that members of more collectivistic cultures-where there is a greater focus on conformity-may have a slightly stronger motive for distinctiveness than do members of more individualistic cultures (although in the next section we consider an alternative possible explanation of these findings).

Notably, the stronger association of distinctiveness with positive affect in more collectivistic cultures argues against an alternative explanation of our findings - that perhaps distinctive aspects of identity would have become especially salient to members of collectivistic cultures precisely because of their inconsistency with cultural values, leading to feelings of social discomfort and shame, and perhaps rumination about these undesired parts of identity. ${ }^{13}$ Had this been the case, participants in more collectivistic nations might still have perceived the more distinctive aspects of their identities as especially central — as we found here- but they surely would have associated them with less rather than more positive affect. Instead, we found that the moderating effect of culture was actually much stronger for predictions of positive affect than it was for predictions of perceived centrality: In fact, when culture was operationalized in terms of values, participants from the most collectivistic cultures in our sample showed a positive relationship between distinctiveness and positive affect that was almost twice as strong as that shown in the most individualistic cultures.

It also does not appear likely to us that the importance of distinctiveness in our collectivistic samples can be reduced to a question of demand characteristics. We took great care to avoid demand characteristics when designing the study. To avoid priming a Western, individualistic conception of self-hood, we developed a culturally decentered alternative to the TST to generate identity content for the current study, making the nature of the task more concrete and contextualized, and emphasizing that relational and collective as well as personal identity aspects were valid answers. To avoid priming the importance of distinctiveness when participants made their ratings of identity centrality and affect, we placed these ratings before the distinctiveness ratings in the questionnaire, and we interspersed the four distinctiveness ratings among 19 other ratings, so that even if participants looked ahead in the questionnaire, our interest in distinctiveness would not have been easily detected. Even if one imagines that these attempts were not $100 \%$ successful, it remains unclear how stable demand characteristics in our study design could have affected our cultural samples differentially to produce the pattern of results we found here.

\section{Sources of Distinctiveness Across Cultures}

Beyond questions about the strength of the distinctiveness motive across cultures, an important goal of our study was to test whether ways of satisfying this motive would vary across cultures. Based on Vignoles et al.'s (2000) predictions, we expected difference, social position, and separateness to be three alternative ways of constructing a sense of distinctiveness and that people would tend to achieve satisfaction of the distinctiveness motive in ways that best fitted their cultural meaning systems. More precisely, Vignoles et al. (2000; Vignoles, 2009) proposed that difference and separateness would be more available, accessible, and valued in individualistic cultures, whereas social position would be more so in collectivistic cultures.

Our results support Vignoles et al.'s (2000) theoretical model of difference, social position, and separateness as alternative ways of constructing a general feeling of distinctiveness, with all three sources emerging as significant predictors of the extent to which participants viewed aspects of their identities as distinguishing them from others. On average across our cultural samples, difference was found to be the strongest source of distinctiveness. This

(SANU; Lynn \& Snyder, 2002), an explicit, self-report measure of the "need" for distinctiveness. We used scores from the SANU as a dependent variable in an additional set of analyses. Results showed that individuals with stronger openness (vs. conservation) values reported that they had a stronger NFU $(B=.09, p<.001)$, whereas there was no effect of culture-level values. No individual- or culture-level moderation effects were found of contextualism beliefs on SANU scores. Thus, in contrast with our more subtle and indirect approach to measuring identity motives, differences in individuals' self-reports of their need for distinctiveness appear to depend on how much an individual values distinctiveness, but they are seemingly not influenced directly by group-level values or beliefs. This additional set of analyses show how results largely differ depending on the explicit versus more indirect character of the scale used to measure distinctiveness. For reasons outlined earlier in this article (based on Vignoles, 2009, 2011), we believe that an indirect measure is a more valid indicator of underlying identity motives.

${ }^{12}$ An additional analysis revealed that this individual-level moderation effect was only found when controlling for the opposing culture-level moderation. Hence, it should be interpreted as an effect of individuals' relative positions on the value scale within their respective cultural groups, not their absolute positions, as $\mathrm{H} 1$ would predict. In contrast, the corresponding culture-level moderation effect was found irrespective of whether or not we controlled for the individual-level moderation.

${ }^{13} \mathrm{We}$ are grateful to an anonymous reviewer of a previous version of this article for suggesting this possibility. 
is in line with the focus in the psychological literature on difference as a source of distinctiveness (e.g., Lynn \& Snyder, 2002), although it may also reflect the relatively young age of our sample-which is also true of the samples of college students that have participated in many previous studies of distinctiveness-seeking. More crucially, in support of Vignoles et al.'s predictions, cultural orientation moderated how distinctiveness was achieved: Whereas people in more individualistic cultures tended to construct distinctiveness more in terms of difference $(\mathrm{H} 4)$, people in more collectivistic cultures tended to construct distinctiveness more in terms of social position (H6). These findings were observed with both values-based and beliefs-based measures of cultural orientation.

The findings regarding separateness as a source of distinctiveness were somewhat more complex, although they were also broadly in line with the predicted pattern. Overall, separateness was a much weaker source of distinctiveness than difference and social position. One possible speculation is that separateness may become more important at later stages in life and that the young age of the present sample explains the relatively small contribution of separateness as a source of distinctiveness. Only partially supporting $\mathrm{H} 5$, we found that the importance of separateness as a way of achieving a sense of distinctiveness was higher in cultures with more individualistic values and among participants from richer nations, whereas it did not vary with contextualism beliefs. The latter result does not support Vignoles et al.'s (2000) hypothesis that beliefs about personhood would predict the extent to which separateness is used as a way to achieve a sense of distinctiveness. Rather, it appears that it is in richer nations, and where independence is not just believed in but valued, that people start to use separateness as a basis for identity construction. These results also support arguments against a monolithic view of individualismcollectivism; they show that it is important to measure diverse facets of individualism-collectivism rather than assuming that each facet will show the same pattern of effects (see Owe et al., in press).

Notably, the fact that distinctiveness is constructed differently in different cultural contexts may provide an alternative explanation of our finding that distinctiveness had a more positive affective significance in collectivistic cultures. If different cultures provide different ways of satisfying this motive, then there is no reason to assume - as Brewer and Roccas (2001) do-that some cultures will be more likely to frustrate the distinctiveness motive. From our perspective, some forms of distinctiveness (i.e., difference, separateness) may be less available in collectivistic cultures, but other forms of distinctiveness (i.e., social position) will be more so. Thus, there is no particular reason to expect that the distinctiveness motive will be chronically more aroused in collectivistic cultures.

Rather than trying to explain why distinctiveness was a stronger predictor of positive affect in collectivistic cultures, we suggest that it may be more productive to ask why distinctiveness was a weaker predictor of positive affect in individualistic cultures. One important difference among the three sources of distinctiveness in our model is that they are likely to be differentially satisfying to other identity motives-particularly the motive for belonging, as one would expect this to be frustrated by identity aspects that separate one from others, but satisfied by identity aspects that give one a clear social position (Becker et al., 2011; Vignoles et al., 2000). We believe that participants in individualistic cultures may have been more affectively ambivalent about distinctiveness because they were basing their distinctiveness to a greater extent on characteristics that would probably have undermined satisfaction of the motive for belonging-and feelings of belonging are an important source of positive affect.

\section{Distinctiveness and Levels of Universality}

So, is the motive for distinctiveness a psychological universal? Norenzayan and Heine (2005) have presented a framework of different levels of universality ranging from non-universals, which are pure cultural inventions, to "accessibility universals," for which there is strictly no cultural variability. In between these two extremes, we suggest that the motive for distinctiveness can be described as a "functional universal"; it is used in the same way across cultures-it serves as a guide to identity construction processes-even if the size of this effect may be subject to cultural variation-slightly stronger, if anything, in more collectivistic cultures. This indeed speaks in favor of a universalist view on distinctiveness and, by extension, on identity motives in general (see also Brewer, 1991; Sedikides, Gaertner, \& Toguchi, 2003; Vignoles, 2011).

Nonetheless, over and above this universal quality of the underlying motive for distinctiveness, we have observed systematic cultural variation in the ways in which the motive is satisfied. This illustrates the importance of concentrating on the right level of abstraction to discover universal psychological principles (Kenrick, Nieuweboer, \& Buunk, 2010; Norenzayan \& Heine, 2005). More precisely, it supports Vignoles's $(2009,2011)$ portrayal of identity motives - including the distinctiveness motive-as "culturally flexible universals." He argues that people in all cultures are guided by a common set of underlying identity motives (thus, they are universal) but that cultural groups will develop different, culturally attuned ways of satisfying the motives (thus, they are flexible). In this way, the same underlying motive can have very different consequences in different cultural environments, leading to important cross-cultural variation in the outcomes of identity processes. A similar view has been introduced by Kenrick et al. (2010) with their metaphor of the human mind as a coloring book-the outlines of the book being there from the start but cultural norms defining the particular colors drawn inside these outlines. The rationale of culturally flexible universals could be extended to other identity motives as well; some research on self-esteem (e.g., Sedikides et al., 2003) and continuity (e.g., Chandler, Lalonde, Sokol, \& Hallett, 2003) is already taking a similar route.

\section{Considering Culture on Multiple Levels of Analysis}

To take culture into account when studying psychological processes is not a straightforward task. To date, much cross-cultural research consists in describing psychological differences between samples of two or more different nationalities-which, although not representative samples, are typically assumed to reflect some posited national profile in terms of culture-and speculating on possible explanations of this variation (Bond, 2009). We used a more theoretically driven approach to studying psychological processes across cultures. 
We measured cultural orientations in a larger number of nations and used both individual scores and group-level means of continuous measures of culture as moderators in our analyses. This has two obvious advantages over the common approach of two-nation comparisons. First, by measuring cultural orientation, we avoid treating samples as reflecting national cultural profiles and, instead, acknowledge their non-representative and more specific character. Second, our multilevel approach to culture makes it possible to test whether it is the "climate" of values and beliefs that prevails in a given context or the individual cultural member's personal internalization of those values and beliefs that makes the difference. Many studies do measure cultural orientations, but they are confined by sampling limitations to examining individual-level mediation, thus presupposing that culture has its effects through a process of individual internalization. A multilevel methodology involving many cultural groups is necessary to distinguish effects of cultural orientation on individual and contextual levels of analysis. Thus, our study enables an actual test of explanations of cultural variation in terms of dimensions of psychological culture.

Although our data analytic strategy equally allowed finding individual-level and cultural-level effects, stronger moderation effects were observed at the cultural level of analysis, with the individual-level effects in most cases being vanishingly small. In other words, while controlling for any potential effects of individual differences in values or beliefs, it was found that the mean values and beliefs of each specific cultural sample had an effect on how distinctiveness was constructed by the individuals within that cultural group. Even in the case of values, for which it would be expected that individuals' priorities largely reflect and internalize the prevalent cultural values of the environment they are raised in (Schwartz \& Bardi, 2001), results show that it is mainly a cultural level of analysis that carries explanatory power over these processes. Thus, the differences we found in ways of constructing a sense of distinctiveness cannot be attributed to individuals' internalization of cultural beliefs and values-instead, they appeared to be effects of living in a particular cultural context where certain things are believed and valued. ${ }^{14}$

This raises interesting questions about the processes that may be underlying these contextual effects on the construction of individual identities. One possibility, suggested by the recently emerging intersubjective culture perspective (Chiu, Gelfand, Yamagishi, Shteynberg, \& Wan, 2010), is that others' beliefs and values may have influenced identity construction through individuals' perceptions of what is normatively believed and valued in their cultural contexts. According to Chiu et al. (2010), perceived cultural norms have an important psychological impact over and above individuals' personal beliefs and values for a variety of reasons: because consensual ideas are interpreted as correct and natural, because social identification with a given cultural group will lead individuals to embrace the group's norms, and as a result of social accountability to others. Although these predictions have been well-supported across a growing number of studies, we are not convinced that intersubjective perceptions will prove to be the mechanism explaining our current findings. Crucially, numerous studies reviewed by Chiu et al. have shown that the intersubjective perceptions of others' beliefs and values that form the main focus of the intersubjective culture approach frequently do not correspond with actual variation in others' beliefs and values-which provided the moderation effects in our study.
Moreover, researchers so far have usually measured these intersubjective perceptions at an individual level of analysis-in other words, individuals may differ in their perceptions of the same cultural environment, and it is through individual-level psychological mechanisms leading to individual-level responses that these perceptions are expected to account for differences both within and across groups. In contrast, the effects that we found were located at the cultural level of analysis, explaining differences in identity construction across cultural groups but not within groups. This suggests that our results might be explained better by an approach that focuses on the emergent properties of cultures as social systems rather than one that focuses on cultures as targets of individual perceptions.

One such systemic approach is the niche construction approach to culture described by Yamagishi (2010). This perspective (formerly known as the institutional approach to culture) suggests that we might understand the different constructions of distinctiveness observed here as aspects of social institutions or niches-selfsustaining systems of shared beliefs, incentives, and social practices. In social systems where people's values are focused on obligations toward others and where a contextualized concept of the person prevails, an individual's everyday life and the incentives surrounding his or her actions will be strongly organized around aspects of their social position-whatever their personal beliefs and values-and hence, in such contexts, it may be relatively adaptive to place a greater emphasis on such aspects when thinking about who one is in relation to others. In contrast, in social systems where people's values are focused on selfdirection and autonomy and where a decontextualized concept of the person prevails, an individual's daily experiences and incentives will be focused to a greater extent on his or her personal characteristics and preferences, and so in these contexts, it may be adaptive to focus to a greater extent on differences in personal characteristics when thinking about one's identity.

\footnotetext{
${ }^{14}$ We should acknowledge that our capacity to detect individual-level effects may have been weakened somewhat by the mediocre individuallevel reliabilities of our measures in some samples (see Footnote 3 ). This would likely have reduced the size of the effects that we were able to observe at the individual level, resulting in some loss of statistical power on this level of analysis, and reducing somewhat our ability to control for the potential confounding influence of aggregated individual-level moderation effects when testing the culture-level moderation effects. Yet, most of the individual-level moderation effects were so small that they failed to reach significance even with a sample size of 4,751 individuals-indeed, many of the these effects were estimated at exactly .00. Although lower reliabilities might weaken these effects, they would not be expected to eliminate them entirely given that we had a sufficient sample size to detect even very small effects. We should also emphasize that not only were the effect sizes different at the two levels of analysis but the actual pattern of findings was different. Thus, even if the true individual-level moderation effects were substantially stronger than those reported here, aggregating these effects to the cultural level still could not account for the pattern of culture-level effects observed here. Hence, we are confident that our results truly represent effects of living within a particular cultural contextindependent of one's personal, internalized values and beliefs - and that they are not simply artifacts of the differential reliability of our measures across the levels of analysis.
} 


\section{Limitations and Future Directions}

We should note several limitations of the current study. First, our findings are based on cross-sectional data, and so we cannot be certain about the causal direction of our findings. Although Vignoles et al. (2006) have previously provided longitudinal evidence for the causal role of the distinctiveness motive in identity construction, the focus of the current study was on the magnitude of the observed relationships, not their causal direction.

Second, our participants were mostly high school students, and thus the results may not generalize to older and/or less advantaged groups. Although high school students are likely to be more diverse in terms of socioeconomic status and ethnic diversity than university students, they are still a selective group, especially in some nations. Moreover, in the sample from the Philippines, which was the second poorest nation in the study, participants were in fact university students. Thus, in this nation in particular, it is likely that our participants were from more advantaged social groups. In terms of age, one might expect that emphases in identity construction would change according to life stage (e.g., Erikson, 1980), and thus we should be cautious about generalizing the present results to other age groups. In an ongoing study, we are currently collecting data from an adult sample, which should enable us to examine how the distinctiveness motive operates and is satisfied among adults in diverse cultural contexts.

Third, with a multilevel approach to data analysis, it is important to consider sample sizes on each level of analysis. Although the number of participants in this study was high, our Level 3 sample size was relatively low (21 cultural samples). So far, there is no consensus in the literature regarding power calculations for multilevel modeling, but it has been suggested that around 20 samples provide sufficient power to detect cross-level interactions in multilevel analysis (Kreft \& de Leeuw, 1998). Indeed, Maas and Hox (2005) concluded from their two-level simulation study that, even for relatively small Level 2 sample sizes, estimates of regression coefficients, standard errors of the latter, and variance components appear to be accurate. In the case of the present study, low statistical power did not seem to be a problem, as most of our hypothesis tests yielded clear results based on conventional criteria of statistical significance. Still, our findings included one marginally significant result, relating to whether culture-level contextualism beliefs moderate the importance of the distinctiveness as a predictor of perceived centrality. Hence, it will be valuable to test whether this result is replicated in future research involving a larger sample of cultural groups.

In future research, it would also be desirable to collect data on intersubjective perceptions of cultural beliefs and values in addition to participants' own beliefs and values. This would allow us to evaluate to what extent the contextual moderation effects that we observed here are mediated by individuals' perceptions of cultural norms, as suggested by the intersubjective culture approach, or to what extent they may be better explained by macrolevel, systemic processes. Additionally, it will be important to examine to what extent a similar approach can be applied to other identity motives. According to MICT (Vignoles, 2011; Vignoles, Manzi, Regalia, Jemmolo, \& Scabini, 2008; Vignoles et al., 2006), the distinctiveness motive is just one of at least six motives that guide the processes shaping identity, and each of the other five motives is predicted to function similarly as a "culturally flexible universal." Further analyses from the current study, and from our ongoing study among adults, will test to what extent motives for self-esteem, continuity, belonging, efficacy, and meaning generalize across cultures with differing values and beliefs, as well as the routes to motive satisfaction that different cultures provide for some of these other motives.

To conclude, the current study demonstrates the importance of attending to the multifaceted nature of distinctiveness-seeking and of taking cultural context into account when investigating the operation of the distinctiveness motive. In particular, the results show how, within any given cultural context, individuals construct their sense of distinctiveness in culturally appropriate ways. In line with the idea of "universalism without the uniformity" (Shweder \& Sullivan, 1993), it seems that people across the world seek the same thing, only in different ways.

\section{References}

Aiken, L. S., \& West, S. G. (1991). Multiple regression: Testing and interpreting interactions. Thousand Oaks, CA: Sage.

Becker, M., Easterbrook, M., Vignoles, V. L., Owe, E., Brown, R., Smith, P. B., . . B Bourguignon, D. (2011, July). Motivational conflict between distinctiveness and belonging: Fundamental or cultural? Paper presented at the 16th General Meeting of the European Association of Social Psychology, Stockholm, Sweden.

Bond, M. H. (2009). Circumnavigating the psychological globe: From yin and yang to starry, starry night. In S. Bekman \& A. Aksu-koc (Eds.), Perspectives on human development, family, and culture (pp. 31-49). doi:10.1017/CBO9780511720437.006

Bond, M. H., Leung, K., Tong, K., de Carrasquel, S. R., Murakami, F., Yamaguchi, S., . . Lewis, J. R. (2004.). Culture-level dimensions of social axioms and their correlates across 41 cultures. Journal of CrossCultural Psychology, 35, 548-570. doi:10.1177/0022022104268388

Breakwell, G. M. (1987). Identity. In H. Beloff \& A. Coleman (Eds.), Psychology survey 6 (pp. 94-114). Leicester, United Kingdom: British Psychological Society.

Brewer, M. B. (1991). The social self: On being the same and different at the same time. Personality and Social Psychology Bulletin, 17, 475482. doi:10.1177/0146167291175001

Brewer, M. B., \& Chen, Y. R. (2007). Where (who) are collectives in collectivism? Toward conceptual clarification of individualism and collectivism. Psychological Review, 114, 133-151. doi:10.1037/0033295X.114.1.133

Brewer, M. B., \& Pickett, C. L. (1999). Distinctiveness motives as a source of the social self. In T. R. Tyler, R. M. Kramer, \& O. P. John (Eds.), The psychology of the social self (pp. 71-87). Mahwah, NJ: Erlbaum.

Brewer, M. B., \& Roccas, S. (2001). Individual values, social identity, and optimal distinctiveness. In C. Sedikides \& M. B. Brewer (Eds.), Individual self, relational self, collective self (pp. 219-237). New York, NY: Psychology Press.

Burns, D. J., \& Brady, J. (1992). A cross-cultural comparison of the need for uniqueness in Malaysia and the United States. The Journal of Social Psychology, 132, 487-495. doi:10.1080/00224545.1992.9924728

Chandler, M. J., Lalonde, C. E., Sokol, B., \& Hallett, D. (2003). Personal persistence, identity development, and suicide: A study of Native and non-Native North American adolescents. Monographs of the Society for Research in Child Development, 68(2, Serial No. 273).

Chinese Culture Connection. (1987). Chinese values and the search for culture-free dimensions of culture. Journal of Cross-Cultural Psychology, 18, 143-164. doi:10.1177/0022002187018002002

Chiu, C.-Y., Gelfand, M. J., Yamagishi, T., Shteynberg, G., \& Wan, C. (2010). Intersubjective culture: The role of intersubjective perceptions in 
cross-cultural research. Perspectives on Psychological Science, 5, 482493. doi: $10.1177 / 1745691610375562$

Cooper, M. L. (2010). Toward a person $\times$ situation model of sexual risk-taking behaviors: Illuminating the conditional effects of traits across sexual situations and relationship contexts. Journal of Personality and Social Psychology, 98, 319-341. doi:10.1037/a0017785

Erikson, E. H. (1980). Identity and the life cycle. New York, NY: Norton. Eriksson, E. L., Becker, M., \& Vignoles, V. L. (2011). Just another face in the crowd? Distinctiveness seeking in Sweden and Britain. Psychological Studies, 56, 125-134. doi:10.1007/s12646-010-0030-5

Firebaugh, G. (1980). Groups as contexts and frog ponds. In K. H. Roberts \& L. Burstein (Eds.), Issues in aggregation (pp. 43-52). San Francisco, CA: Jossey-Bass.

Fischer, R. (2011). Value isomorphism in the European Social Survey: Exploration of meaning shifts in values across levels. Journal of CrossCultural Psychology. Advance online publication. doi:10.1177/ 0022022111413276

Fischer, R., Vauclair, C.-M., Fontaine, J. R. J., \& Schwartz, S. H. (2010). Are individual-level and country-level value structures different? Testing Hofstede's legacy with the Schwartz Value Survey. Journal of Cross-Cultural Psychology, 41, 135-151. doi:10.1177/ 0022022109354377

Fontaine, J. R. J., Poortinga, Y. H., Delbeke, L., \& Schwartz, S. H. (2008). Structural equivalence of the values domain across cultures: Distinguishing sampling fluctuations from meaningful variation. Journal of CrossCultural Psychology, 39, 345-365. doi:10.1177/0022022108318112

Fromkin, H. L. (1970). Effects of experimentally aroused feelings of undistinctiveness upon valuation of scarce and novel experiences. Journal of Personality and Social Psychology, 16, 521-529. doi:10.1037/ h0030059

Fromkin, H. L. (1972). Feelings of interpersonal undistinctiveness: An unpleasant affective state. Journal of Experimental Research in Personality, 6, 178-185.

Geertz, C. (1975). On the nature of anthropological understanding. American Scientist, 63, 47-53

Gheorghiu, M. A., Vignoles, V. L., \& Smith, P. B. (2009). Beyond the United States and Japan: Testing Yamagishi's emancipation theory of trust across 31 nations. Social Psychology Quarterly, 72, 365-383. doi: $10.1177 / 019027250907200408$

Heine, S. J., Lehman, D. R., Markus, H. R., \& Kitayama, S. (1999). Is there a universal need for positive self-regard? Psychological Review, 106, 766-794. doi:10.1037/0033-295X.106.4.766

Heine, S. J., Lehman, D. R., Peng, K., \& Greenholtz, J. (2002). What's wrong with cross-cultural comparisons of subjective Likert scales? The reference-group effect. Journal of Personality and Social Psychology, 82, 903-918. doi:10.1037/0022-3514.82.6.903

Ho, D. Y. F. (1993). Relational orientation in Asian social psychology. In U. Kim \& J. W. Berry (Eds.), Indigenous psychologies: Research and experience in cultural context (pp. 240-259). Newbury Park, CA: Sage.

Hofer, J., \& Bond, M. H. (2008). Do implicit motives add to our understanding of psychological and behavioral outcomes within and across cultures? In R. M. Sorrentino \& Susumu Yamaguchi (Eds.), Handbook of motivation and cognition across cultures (pp. 95-118). Amsterdam, the Netherlands: Elsevier.

Hofmann, D. A., \& Gavin, M. B. (1998). Centering decisions in hierarchical linear models: Implications for research in organizations. Journal of Management, 24, 623-641. doi:10.1177/014920639802400504

Hofstede, G. (1980). Culture's consequences: International studies of work-related values. Newbury Park, CA: Sage.

Hofstede, G. (2001). Culture's consequences: Comparing values, behaviors, institutions and organizations across nations. Beverly Hills, CA: Sage.

Hofstede, G. (2006). What did GLOBE really measure? Researchers' minds versus respondents' minds. Journal of International Business Studies, 37, 882-896. doi:10.1057/palgrave.jibs.8400233

House, R. J., Hanges, P. J., Javidan, M., Dorfman, P. W., \& Gupta, V. (Eds.). (2004). Culture, leadership, and organizations: The GLOBE study of 62 societies. Thousand Oaks, CA: Sage.

Hox, J. J. (2002). Multilevel analysis techniques and applications. Mahwah, NJ: Erlbaum.

Hsu, F. L. K. (1985). The self in cross-cultural perspective. In A. J. Marsella, G. DeVos, \& F. L. K. Hsu (Eds.), Culture and self: Asian and Western perspectives (pp. 24-55). New York, NY: Tavistock.

Javidan, M., House, R. J., Dorfman, P. W., Hanges, P. J., \& Sully de Luque, M. (2006). Conceptualizing and measuring cultures and their consequences: A comparative reviews of GLOBE's and Hofstede's approaches. Journal of International Business Studies, 37, 897-914. doi:10.1057/palgrave.jibs. 8400234

Jetten, J., Postmes, T., \& McAuliffe, B. J. (2002). "We're all individuals": Group norms of individualism and collectivism, levels of identification and identity threat. European Journal of Social Psychology, 32, 189 207. doi:10.1002/ejsp. 65

Jetten, J., Spears, R., \& Postmes, T. (2004). Intergroup distinctiveness and differentiation: A meta-analytic integration. Journal of Personality and Social Psychology, 86, 862-879. doi:10.1037/0022-3514.86.6.862

Jetten, J., Summerville, N., Hornsey, M. J., \& Mewse, A. J. (2005). When differences matter: Intergroup distinctiveness and the evaluation of impostors. European Journal of Social Psychology, 35, 609-620. doi: 10.1002/ejsp.282

Kenrick, D. T., Nieuweboer, S., \& Buunk, A. P. (2010). Universal mechanisms and cultural diversity: Replacing the blank slate with a coloring book. In M. Schaller, A. Norenzayan, S. J. Heine, T. Yamagishi, \& T. Kameda (Eds.), Evolution, culture, and the human mind (pp. 257-272). Mahwah, NJ: Erlbaum.

Kim, H., \& Markus, H. R. (1999). Deviance or uniqueness, harmony or conformity? A cultural analysis. Journal of Personality and Social Psychology, 77, 785-800. doi:10.1037/0022-3514.77.4.785

Kitayama, S., Park, H., Sevincer, A. T., Karasawa, M., \& Uskul, A. K. (2009). A cultural task analysis of implicit independence: Comparing North America, Western Europe, and East Asia. Journal of Personality and Social Psychology, 97, 236-255. doi:10.1037/a0015999

Knafo, A., Schwartz, S. H., \& Levine, R. V. (2009). Helping strangers is lower in embedded cultures. Journal of Cross-Cultural Psychology, 40, 875-879. doi:10.1177/0022022109339211

Krause, S., Back, M. D., Egloff, B., \& Schmukle, S. C. (2011). Reliability of implicit self-esteem measures revisited. European Journal of Personality, 25, 239-251. doi:10.1002/per.792

Kreft, I., \& de Leeuw, J. (1998). Introducing multilevel modeling. Thousand Oaks, CA: Sage.

Kuhn, M. H., \& McPartland, T. S. (1954). An empirical investigation of self-attitudes. American Sociological Review, 19, 68-76. doi:10.2307/ 2088175

LeBel, E. P., \& Gawronski, B. (2009). How to find what's in a name: Scrutinizing the optimality of five scoring algorithms for the name-letter task. European Journal of Personality, 23, 85-106. doi:10.1002/per.705

Leung, K., Bond, M. H., de Carrasquel, S. R., Munoz, C., Hernandez, M., Murakami, F., . . Singelis, T. M. (2002). Social axioms: The search for universal dimensions of general beliefs about how the world functions. Journal of Cross-Cultural Psychology, 33, 286-302. doi:10.1177/ 0022022102033003005

Leyens, J.-P., Yzerbyt, V. Y., \& Rogier, A. (1997). Personality traits that distinguish you and me are better memorized. European Journal of Social Psychology, 27, 511-522. doi:10.1002/(SICI)1099-0992(199709/ 10)27:5<511::AID-EJSP827>3.0.CO;2-7

Lo, C., Helwig, C. C., Chen, S. X., Ohashi, M. M., \& Cheng, C. M. (2011) A needs-based perspective on cultural differences in identity formation. Identity, 11, 211-230. doi:10.1080/15283488.2011.594782 
Lynn, M., \& Snyder, C. R. (2002). Uniqueness seeking. In C. R. Snyder \& S. J. Lopez (Eds.), Handbook of positive psychology (pp. 395-410). New York, NY: Oxford University Press.

Maas, C. J. M., \& Hox, J. J. (2005). Sufficient sample sizes for multilevel modeling. Methodology: European Journal of Research Methods for the Behavioral and Social Sciences, 1, 86-92. doi:10.1027/16142241.1.3.86

Markus, H. R., \& Kitayama, S. (1991). Culture and the self: Implications for cognition, emotion, and motivation. Psychological Review, 98, 224253. doi: $10.1037 / 0033-295 X .98 .2 .224$

Markus, H., \& Kunda, Z. (1986). Stability and malleability of the selfconcept. Journal of Personality and Social Psychology, 51, 858-866. doi:10.1037/0022-3514.51.4.858

Marques, J. M., \& Paez, D. (1994). The "black sheep effect": Social categorization, rejection of ingroup deviates, and perception of group variability. European Review of Social Psychology, 5, 37-68. doi: 10.1080/14792779543000011

McClelland, G. H., \& Judd, C. M. (1993). Statistical difficulties of detecting interactions and moderator effects. Psychological Bulletin, 114, 376-390. doi:10.1037/0033-2909.114.2.376

McGuire, W. J., \& Padawer-Singer, A. (1976). Trait salience in the spontaneous self-concept. Journal of Personality and Social Psychology, 33, 743-754. doi:10.1037/0022-3514.33.6.743

Miller, J. G. (1984). Culture and the development of everyday social explanation. Journal of Personality and Social Psychology, 46, 961978. doi:10.1037/0022-3514.46.5.961

Norenzayan, A., \& Heine, S. J. (2005). Psychological universals: What are they and how can we know? Psychological Bulletin, 131, 763-784. doi:10.1037/0033-2909.131.5.763

Owe, E., Vignoles, V. L., Becker, M., Brown, R., Smith, P. B., Lee, S. W. S., ... Jalal, B. (in press). Contextualism as an important facet of individualism-collectivism: Personhood beliefs across 37 national groups. Journal of Cross-Cultural Psychology. doi:10.1177/ 00220022111430255

Petavratzi, F. (2004). Implicit and explicit distinctiveness motivation and romantic partner preferences (Unpublished BA dissertation). University of Sussex, Brighton, United Kingdom

Pickett, C. L., Silver, M., \& Brewer, M. B. (2002). The impact of assimilation and differentiation needs on perceived group importance and judgments of ingroup size. Personality and Social Psychology Bulletin, 28, 546-558. doi:10.1177/0146167202287011

Powell, F. A. (1974). The perception of self-uniqueness as a determinant of message choice and valuation. Speech Monographs, 41, 163-168. doi: 10.1080/03637757409375831

Raudenbush, S. W. (1989). "Centering" predictors in multilevel analysis: Choices and consequences. Multilevel Modelling Newsletter, 1(2), $10-12$.

Raudenbush, S. W., Bryk, A. S., \& Congdon, R. T. (2007). HLM 6: Hierarchical linear and nonlinear modeling. Lincolnwood, IL: Scientific Software International.

Salvatore, J., \& Prentice, D. (2011). The independence paradox. In J. Jetten \& M. J. Hornsey (Eds.), Rebels in groups: Dissent, deviance, difference and defiance (pp. 201-218). Chichester, England: Wiley-Blackwell.

Schwartz, S. H. (1992). Universals in the content and structure of values: Theoretical advances and empirical tests in 20 countries. In M. P. Zanna (Ed.), Advances in experimental social psychology (Vol. 25, pp. 1-65). San Diego, CA: Academic Press.

Schwartz, S. H. (2004). Mapping and interpreting cultural differences around the world. In H. Vinken, J. Soeters, \& P. Ester (Eds.), Comparing cultures: Dimensions of culture in a comparative perspective (pp. 4373). Boston, MA: Brill.

Schwartz, S. H. (2007). Value orientations: Measurement, antecedents and consequences across nations. In R. Jowell, C. Roberts, R. Fitzgerald, \& G. Eva (Eds.), Measuring attitudes cross-nationally: Lessons from the
European Social Survey (pp. 161-193). London, England: Sage. doi: 10.4135/9781849209458.n9

Schwartz, S. H., \& Bardi, A. (2001). Value hierarchies across cultures: Taking a similarities perspective. Journal of Cross-Cultural Psychology, 32, 268-290. doi:10.1177/0022022101032003002

Schwartz, S. H., \& Rubel, T. (2005). Sex differences in value priorities: Cross-cultural and multimethod studies. Journal of Personality and Social Psychology, 89, 1010-1028. doi:10.1037/0022-3514.89.6.1010

Sedikides, C., Gaertner, L., \& Toguchi, Y. (2003). Pancultural selfenhancement. Journal of Personality and Social Psychology, 84, 60-79. doi:10.1037/0022-3514.84.1.60

Shweder, R. A., \& Bourne, E. J. (1984). Does the concept of the person vary cross-culturally? In R. A. Shweder \& R. A. LeVine (Eds.), Culture theory: Essays on mind, self, and emotion (pp. 158-199). Cambridge, England: Cambridge University Press.

Shweder, R. A., \& Sullivan, M. A. (1993). Cultural psychology: Who needs it? Annual Review of Psychology, 44, 497-523. doi:10.1146/ annurev.ps.44.020193.002433

Singelis, T. M., Triandis, H. C., Bhawuk, D. P. S., \& Gelfand, M. J. (1995) Horizontal and vertical dimensions of individualism and collectivism: A theoretical and measurement refinement. Cross-Cultural Research, 29, 240-275. doi:10.1177/106939719502900302

Smith, P. B. (2004a). Acquiescent response bias as an aspect of cultural communication style. Journal of Cross-Cultural Psychology, 35, 50-61. doi: $10.1177 / 0022022103260380$

Smith, P. B. (2004b). Nations, cultures, and individuals: New perspectives and old dilemmas. Journal of Cross-Cultural Psychology, 35, 6-12. doi: $10.1177 / 0022022103260460$

Smith, P. B. (2011). Cross-cultural perspectives on identity. In S. J. Schwartz, K. Luyckx, \& V. L. Vignoles (Eds.), Handbook of identity theory and research (pp. 249-265). doi:10.1007/978-1-4419-7988-9_11

Smith, P. B., Bond, M. H., \& Kağitçibaşi, Ç. (2006). Understanding social psychology across cultures: Living and working in a changing world. London, England: Sage.

Smith, P. B., \& Schwartz, S. H. (1997). Values. In J. W. Berry, M. H. Segall, \& Ç. Kağitçibaşi (Eds.), Handbook of cross-cultural psychology (2nd ed., Vol. 3, pp. 77-118). Boston, MA: Allyn \& Bacon.

Snyder, C. R., \& Endelman, J. R. (1979). Effects of degree of interpersonal similarity on physical distance and self-reported attraction: A comparison of uniqueness and reinforcement theory predictions. Journal of Personality, 47, 492-505. doi:10.1111/j.1467-6494.1979.tb00628.x

Snyder, C. R., \& Fromkin, H. L. (1980). Uniqueness: The human pursuit of difference. New York, NY: Plenum Press.

Stephens, N. M., Markus, H. R., \& Townsend, S. S. M. (2007). Choice as an act of meaning: The case of social class. Journal of Personality and Social Psychology, 93, 814-830. doi:10.1037/0022-3514.93.5.814

Tafarodi, R. W., Marshall, T. C., \& Katsura, H. (2004). Standing out in Canada and Japan. Journal of Personality, 72, 785-814. doi:10.1111/ j.0022-3506.2004.00280.x

Tajfel, H., \& Turner, J. C. (1986). The social identity theory of intergroup behavior. In S. Worchel \& W. G. Austin (Eds.), Psychology of inter group relations (pp. 7-24). Chicago, IL: Nelson-Hall.

Takano, Y., \& Osaka, E. (1999). An unsupported common view: Comparing Japan and the U.S. on individualism/collectivism. Asian Journal of Social Psychology, 2, 311-341. doi:10.1111/1467-839X.00043

Triandis, H. C. (1995). Individualism and collectivism. Boulder, CO: Westview Press.

Triandis, H. C., Chan, D. K.-S., Bhawuk, D. P. S., Iwao, S., \& Sinha J. B. P. (1995). Multimethod probes of allocentrism and idiocentrism. International Journal of Psychology, 30, 461-480. doi:10.1080/ 00207599508246580

Turnbull, W., Miller, D. T., \& McFarland, C. (1990). Populationdistinctiveness, identity, and bonding. In J. M. Olson \& M. P. Zanna 
(Eds.), Self-inference processes: Ontario Symposium on Personality and Social Psychology (Vol. 6, pp. 115-133). Hillsdale, NJ: Erlbaum.

United Nations Educational, Scientific and Cultural Organization. (2010). UNESCO Institute for Statistics Data Centre. Retrieved from http:// stats.uis.unesco.org/unesco/TableViewer/document.aspx?ReportId= $143 \& I F \_$Language $=$eng

van Rijswijk, W., Haslam, S. A., \& Ellemers, N. (2006). Who do we think we are? The effects of social context and social identification on ingroup stereotyping. British Journal of Social Psychology, 45, 161-174. doi:10.1348/014466605X39475

Vignoles, V. L. (2009). The motive for distinctiveness: A universal, but flexible human need. In S. J. Lopez \& C. R. Snyder (Eds.), Oxford handbook of positive psychology (Vol. 2, pp. 491-499). New York, NY: Oxford University Press.

Vignoles, V. L. (2011). Identity motives. In S. J. Schwartz, K. Luyckx, \& V. L. Vignoles (Eds.), Handbook of identity theory and research (pp. 403-432). doi:10.1007/978-1-4419-7988-9_18

Vignoles, V. L., Chryssochoou, X., \& Breakwell, G. M. (2000). The distinctiveness principle: Identity, meaning, and the bounds of cultural relativity. Personality and Social Psychology Review, 4, 337-354. doi: 10.1207/S15327957PSPR0404_4

Vignoles, V. L., Chryssochoou, X., \& Breakwell, G. M. (2002). Sources of distinctiveness: Position, difference and separateness in the identities of Anglican parish priests. European Journal of Social Psychology, 32, 761-780. doi:10.1002/ejsp.119

Vignoles, V. L., Manzi, C., Regalia, C., Jemmolo, S., \& Scabini, E. (2008). Identity motives underlying desired and feared possible future selves. Journal of Personality, 76, 1165-1200. doi:10.1111/j.14676494.2008.00518.x

Vignoles, V. L., \& Moncaster, N. J. (2007). Identity motives and in-group favouritism: A new approach to individual differences in intergroup discrimination. British Journal of Social Psychology, 46, 91-113. doi: 10.1348/014466605X85951

Vignoles, V. L., Regalia, C., Manzi, C., Golledge, J., \& Scabini, E. (2006). Beyond self-esteem: Influence of multiple motives on identity construction. Journal of Personality and Social Psychology, 90, 308-333. doi: 10.1037/0022-3514.90.2.308

Walsh, P. E., \& Smith, J. L. (2007). Opposing standards within the cultural worldview: Terror management and American women's desire for uniqueness versus inclusiveness. Psychology of Women Quarterly, 31, 103-113. doi:10.1111/j.1471-6402.2007.00335.x

Weber, M. (1958). The Protestant ethics and the spirit of capitalism. New York, NY: Scribner's. (Original work published 1905)

Welzel, C. (2010). How selfish are self-expression values? A civicness test. Journal of Cross-Cultural Psychology, 41, 152-174. doi:10.1177/ 0022022109354378

World Bank. (2010). GNI per capita 2007, Atlas method. Retrieved from http://data.worldbank.org/indicator/NY.GNP.PCAP.CD

Yamagishi, T. (2010). Micro-macro dynamics of the cultural construction of reality: A niche construction approach to culture. In M. J. Gelfand, C.-Y. Chiu, \& Y.-Y Hong (Eds.), Advances in culture psychology (Vol. 1, pp. 251-308). Oxford, England: Oxford University Press.

Yamagishi, T., Hashimoto, H., \& Schug, J. (2008). Preferences versus strategies as explanations for culture-specific behavior. Psychological Science, 19, 579-584. doi:10.1111/j.1467-9280.2008.02126.x

Yamaguchi, S., Kuhlman, D. M., \& Sugimori, S. (1995). Personality correlates of allocentric tendencies in individualist and collectivist cultures. Journal of Cross-Cultural Psychology, 26, 658-672. doi:10.1177/ 002202219502600609 


\section{Appendix A}

Zero-Order Correlations Between Ratings of Identity Aspects $(N=\mathbf{5 1 , 5 8 0})$ for Perceived Centrality, Positive Affect, General Distinctiveness, Difference, Separateness, and Social Position

\begin{tabular}{lcccccc}
\hline \multicolumn{1}{c}{ Variable } & 1 & 2 & 3 & 4 & 5 & 6 \\
\hline 1. Perceived centrality & - & .46 & .33 & .29 & .05 & .35 \\
2. Positive affect & .48 & - & .26 & .29 & -.08 & .43 \\
3. General distinctiveness & .36 & .29 & - & .45 & .17 & .31 \\
4. Difference & .30 & .29 & .50 & - & .20 & .43 \\
5. Separateness & .09 & -.02 & .21 & .28 & - & .09 \\
6. Social position & .35 & .41 & .39 & .53 & .22 & - \\
\hline
\end{tabular}

Note. Values below the diagonal use raw ratings, and values above the diagonal use participant mean-centered values. All coefficients are significant at $p<.001$.

\section{Appendix B}

Zero-Order Correlations Between Individual-Level Variables $(N=\mathbf{5 , 1 5 8 )}$

\begin{tabular}{lcccc}
\hline \multicolumn{1}{c}{ Variable } & 1 & 2 & 3 & 4 \\
\hline 1. Openness (vs. Conservation) values & $-\overline{-}^{* * * *}$ & & \\
2. Contextualism beliefs & $-.16^{* * * *}$ & $-.06^{* * *}$ & - & \\
3. Gender & $-06^{* * * *}$ & -.02 & $.05^{* * * *}$ & - \\
4. Subjective wealth & .02 &
\end{tabular}

${ }^{a}$ Dummy coded as $-1=$ female, $1=$ male.

*** $p<.01 .{ }^{* * * *} p<.001$.

\section{Appendix C}

Zero-Order Correlations Between Culture-Level Variables $(N=21)$

\begin{tabular}{|c|c|c|c|}
\hline Variable & 1 & 2 & 3 \\
\hline 1. Openness (vs. Conservation) values & - & & \\
\hline 2. Contextualism beliefs & $-.49^{*}$ & - & \\
\hline 3. GNI per capita & .37 & -.26 & - \\
\hline
\end{tabular}

Received September 16, 2010

Revision received August 16, 2011

Accepted September 23, 2011 